\title{
Temporal and Kinematic Properties of Motor Behavior Reflected in Mentally Simulated Action
}

\author{
Lawrence M. Parsons
}

\begin{abstract}
Related perceptual, motor, and cognitive performances were examined to reveal the accuracy of the properties of action spontaneously represented when mentally simulating moving one's hand. The kinematic configuration of the body represented and transformed in mental simulations was not fixed or canonical but corresponded to one's current configuration. Mental simulation time mimicked movement time for natural efficient movement from a posture midway between each of the hand's joint limits into many other postures. Equal time was required for simulated and real movements into more common, comfortable postures; shorter but proportional time was required for simulated movement than real movement into less common postures that involved longer trajectories, coordinated activity at more joints, motion near extremes of joint limits, and uncomfortable kinesthetic sensations. The findings suggest that sensorimotor structures support mental simulations of actions.
\end{abstract}

Humans can envision an object, scene, or event and then inspect the mental representation in a manner that mimics or reflects real perceptual-motor performance (e.g., Craik, 1943; Craver-Lemley \& Reeves, 1992; Finke \& Shepard, 1986; Franklin \& Tversky, 1990; Kosslyn, 1990; Pinker, 1985). In general, similarity between real perceptual-motor behaviors and their mental simulations makes the simulations useful for planning and prediction (e.g., JohnsonLaird, 1983). In the studies reported here I examined related perceptual, motor, and cognitive performances to reveal the verisimilitude of properties spontaneously represented in mental simulations of one's actions.

People can recognize or discriminate the shapes of objects from different viewpoints in many but not all instances (Cooper, 1989; Lowe, 1987; Palmer, 1989; Rock, 1973, 1986; Ullman, 1989). If the shapes are sufficiently similar, people tend to reorient mentally or physically the objects or themselves in an attempt to compare the shapes at the same viewpoint (Hinton \& Parsons, 1981, 1988; Shepard \& Cooper, 1982; Shepard \& Metzler, 1971). Such shapes can be used in various paradigms to study phenomena such as object recognition; the representation of objects and scenes; the role of spatial transformation in the representation of shape; the geometrical bases of apparent motion and imagined spatial transformation; representation of space and action planning; and motor preparation.

When asked to judge whether a body part belongs to the left or right side of the human body, subjects typically report imagining their own corresponding body part at the orientation of the visual stimulus for comparison (Cooper \& Shepard, 1975; Parsons, 1987a, 1987b; Parsons \& Chou,

I thank the anonymous reviewers whose thoughtful comments enabled a much improved presentation of this research.

Correspondence concerning this article should be addressed to Lawrence M. Parsons, Department of Psychology, University of Texas, Austin, Texas 78712. Electronic mail may be sent to parsons@emx.utexas.edu.
1994; Parsons, Gabrieli, \& Gazzaniga, 1993; Sekiyama, 1982). This introspection has three component assertions: that people compare the stimulus to a mental representation of their own bodies; that they imagine a spatial transformation of their bodies, not of the stimulus; and that they compare the stimulus to a mental representation of the part of their bodies that matches the handedness of the stimulus. (See the Appendix.) In addition, subjects often report kinesthetic sensations during left-right judgments of a hand or foot, especially for stimuli portraying the body part at orientations that are awkward or uncomfortable to adopt physically (Cooper \& Shepard, 1975; Parsons, 1987b; Sekiyama, 1982).

These assertions form part of a processing model of the left-right judgment of a body part and of the mental simulation of one's action and are supported by a variety of evidence (for further detail, see Parsons, 1987a, 1987b; Parsons, Gabrieli, \& Gazzaniga, 1993). For example, there is a strong correlation between (a) the time to simulate mentally on instruction the motion of one's hands, feet, or whole body with an outstretched arm into the orientation of the stimulus without making a left-right judgment, and (b) the time to make a left-right judgment of the stimulus (with no other instructions). When subjects are instructed to perform a process embodying the introspections of subjects making left-right judgments, they produce a pattern of response times very similar to that of the latter subjects.

Furthermore, the time required to mentally simulate one's motion into particular hand (or foot) postures (without a left-right judgment) and the time required for left-right judgments of corresponding stimuli are both highly correlated with people's ratings of the awkwardness or difficulty of movements into a stimulus orientation (Parsons, 1987b). In addition, the time required to make a left-right judgment of a hand (or foot) or to mentally simulate the motion of one's hand (or foot) is often consistent with an analysis that used joint constraints to model simulated trajectory length in three-dimensional space (American Academy of Ortho- 
paedic Surgeons, 1965; Parsons, 1987b). In this analysis, the assumption was made that the time required to simulate mentally one's motion would be proportional to the length of its trajectory. This assumption rests on studies of imagined spatial transformations where the time required to imagine an object's rotation or translation is often proportional to the angle or distance, respectively (Bundeson, Larsen, \& Farrell, 1981; Parsons, 1987c, 1994b, 1994c; Shepard \& Cooper, 1982; Shepard \& Metzler, 1971). This analysis predicted reaction time (RT) by rough approximations of the biomechanically possible rotation angles at the wrist and ankle for sets of nonawkward orientations for three stimulus views of hands and two stimulus views of the foot. A corresponding analysis was performed for awkward orientations. Shorter RTs were observed for stimuli whose orientation could be adopted with shorter trajectories of such motion, and longer RTs were observed for stimuli whose orientation required longer trajectories of such motion to adopt. Overall, these analyses and data were consistent with the hypothesis that observers imagined their hand moving into the orientation of the stimulus through a trajectory like that for actual motion.

This conclusion suggests then that at least some biomechanical properties of limb movement-the joint constraints of one's body-spontaneously influence the mental simulations of one's action, and leads to the question of whether other such properties are spontaneously reflected in mental simulations of one's movement. In the five studies reported here I investigated such possibilities while compensating for limitations of the earlier work.

Three simplifying assumptions of Parsons's (1987b) analysis of the influence of joint constraints on the trajectories subjects mentally simulated were as follows. (1) The angle of rotation for the end of a limb alone (i.e., the wrist or ankle), ignoring displacements at other joints in the limb and body, could be used to predict time to mentally simulate the movement of the hand or foot into an orientation comparable to that depicted in a stimulus. (2) The time to mentally simulate the movement of a limb into the stimulus orientation would be proportional to the size of that rotation angle, as the time to represent mentally the rotation of objects that are not body parts is often proportional to angle (Shepard \& Cooper, 1982). (3) The configuration of hand and arm from which a subject mentally simulates the motion originating was near the posture of their hand during the task or near the posture shown in the upper left of Figure 1a (i.e., the upright back of the hand in the picture plane).

These assumptions may be inaccurate. The dynamical property of one's own movement may not be reflected in so abstract a way in mental representations as the spatial transformation of an object not ordinarily under one's motor control. Assumptions (1) and (2) may be relatively safe when applied to movements with one degree of freedom at one joint (e.g., Gottlieb, Corcos, \& Agrawal, 1989); however, the time course of real movement into many target postures would likely reflect interactive effects of forces and torques, arbitrary changes in angle at more than one joint, changes in hand and limb position as well as orientation, and so on, to produce relations between RT and target posture that would be different from that predicted under the simplifying assumptions in my earlier analysis. In general, it is unclear how the neural structures and computational processes underlying the mental simulation of the action of one's body compare to those underlying the mental representation of the spatial transformations of other objects. Many aspects of one's experiences with information about one's body differ considerably from that for abstract objects, as will be discussed below. Finally, Assumption (3) leaves unclear whether the origin from which subjects initiate mental simulations of their hand is a fixed canonical orientation that happened to match the conditions in the experiment or whether the origin is based on the current configuration of an individual's body. In the current studies, I evaluated how temporal properties of an action are reflected in its mental simulation and evaluate which specific kinematic configuration of one's body is used in those simulations.

In general, purposeful motor behavior is organized in a way that reflects the spatial properties of objects and scenes (for a variety of approaches, see Arbib, 1991; Biederman, 1981; Gallistel, 1980; Gibson, 1966; Hinton \& Parsons, 1988; Jeannerod, 1988; Klatsky, McCloskey, Doherty, Pellegrino, \& Smith, 1987; Paillard, 1991; Saltzman \& Kelso, 1987; Schmidt, 1975; Sedgewick, 1986; Shepard \& Hurwitz, 1984). Furthermore, purposefully organized motor behavior must reflect the coordination of those spatial properties with mental or neural representations of the spatial properties of one's body. The plan for the trajectory of action is typically formulated with respect to visually derived reference frames or spaces (e.g., retinal, head-based, body-based, or scene-based ones). The execution of one's action is often assumed to be organized on spatial information composed in joint or action space (e.g., Bisiach, Capitani, \& Porta, 1985; Goldberg \& Bruce, 1990; Hollerbach, 1990; Jeannerod, 1988; Lacquaniti, 1989; Rosenbaum, 1991; Soechting, 1989), and is typically performed with on-line feedback from visual and other sensory error signals. The plans for kinematic and dynamic aspects of an action trajectory are also likely to be based on an internal model of the moved body parts (An, Atkeson, \& Hollerbach, 1988; Clark \& Horch, 1986; Kawato, Maeda, Uno, \& Suzuki, 1990). Neural representations of the spatial properties of one's body are based on a combination of information from proprioceptive, kinesthetic, muscular, visual, articular, postural, tactile, cutaneous, vestibular, equilibrium, and auditory senses, as well as from our sense of physical effort and from contact with objects and among our body parts. A variety of hypotheses about the sources and nature of such representations have been advanced; see, for example, Ballard (1986), Denny-Brown and Chambers (1958), Howard (1986), Kelso (1978), Lackner (1988), Marr and Vaina (1982), Parsons (1990), Parsons and Shimojo (1987, 1994), and Saltzman (1979).

\section{Experiments $1-5$}

These experiments compare the time required for both the mental simulation of many hand and arm movements and 
the corresponding real movements. The conditions in these studies sample systematically and widely the set of all possible target hand postures often from an initial posture where the hand is intermediate between extremes of each of its joint-limited degrees of freedom (i.e., in its anatomical "resting" posture). In the first two studies, I examined the degree to which temporal properties of unconstrained movement are reflected in corresponding mental simulations. In Experiment 3, I assessed the effect of two potential sources of measurement error on the pattern of real movement times in Experiments 1, 2, and 5.

In Experiments 4 and 5, I studied more closely how kinematic properties of action are reflected in mental simulations. An important clue as to the nature of the representations involved in imagined spatial transformations of one's body is whether the original orientation from which one imagines one's body part move is its current instantaneous orientation or a fixed long-term canonical orientation. If the origin of imagined spatial transformations of one's hand is a fixed canonical orientation, then the body representations involved are in a form like that variously hypothesized for other objects (e.g., Cooper \& Shepard, 1973; Jolicoeur, 1985; Palmer, Rosch, \& Chase, 1981; Perrett et al., 1985; Tarr \& Pinker, 1989; Ullman, 1989). However, if the origin of imagined spatial transformations of one's hand is its current orientation, then the representations are continuously updated and are based on nonvisual information that is mapped to the visual information from the target stimulus, because one's hand is not visible during the leftright judgments or the mentally simulated actions.

In the task requiring real movement, subjects were instructed to move their hand and arm in a natural and efficient way into the orientation depicted in the stimulus. A comparable instruction was given in the task requiring only the mental simulation of one's action. It was assumed that these instructions would produce real movement that was likely to be closest to that spontaneously mentally simulated in the left-right judgment task (where no mental simulation instruction was given), and that the speed, extent, and smoothness of the movement in the real movement task and in the mentally simulated task would be approximately the same. In addition, by letting subjects spontaneously modulate the actions that they physically performed and mentally simulated, these initial studies may reveal what properties of real movements are reflected in mental simulations under ecologically valid conditions. It will be informative in later studies to systematically vary the instruction given to subjects in order to manipulate the characteristics of movement (Schmidt, 1988) and to record the manner in which the temporal and kinematic properties of the real movement are reflected in their mental simulations.

\section{Experiment 1: Time for Left-Right Judgment of a Disoriented Hand Mimics Time for Real Movement Into Its Orientation}

In this experiment, I measured the time for a subject to move his or her hand from a task-specific posture into the orientation of a stimulus (of known handedness) and compared it to the time to make left-right judgments of those stimuli by spontaneously imaging movements into those stimulus orientations.

\section{Method}

Subjects. Twenty University of Texas at Austin undergraduates who had not been in any related studies volunteered to participate.

Stimuli. Drawings of a left and right hand viewed from six cardinal perspectives (Figures 1 and 2) were presented in 12 orientations: upright and upside down, and at $30^{\circ}, 60^{\circ}, 90^{\circ}, 120^{\circ}$, and $150^{\circ}$ from upright in clockwise and counterclockwise directions. Left and right hands were mirror images of each other but otherwise identical for each view. Photographic slides of a stimulus subtended about $4^{\circ}$ of visual angle when illuminated by a slide projector (with attached tachistoscopic shutter).

Design. Each subject first performed three replications of the unique 144 real movement trials blocked so that 72 left-hand stimuli alternated with 72 right-hand stimuli. In these blocks, stimulus view and orientation were equally represented and randomly ordered for each subject. Each subject then performed three replications with the 144 stimuli in the left-right judgment condition. In each replication, the stimuli were randomized with respect to handedness, orientation, and view, in an order unique for each subject. Trials on which subjects made errors were repeated later in a block until performed correctly. In both tasks, the first replication was practice.

Procedure. At the start of a real movement trial, subjects' hands were palm down on the edge of a table, with their right foot on a microswitch on the floor. A trial began with the rear-projection of a stimulus on a vertical screen; in response, subjects moved
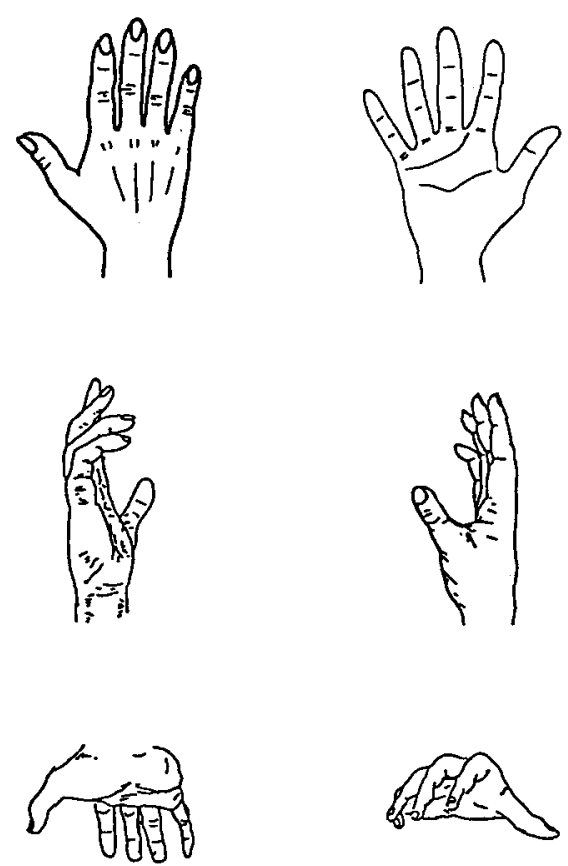

Figure 1. Stimuli portraying a right hand at the $0^{\circ}$ picture plane orientation. Clockwise from top left: back in picture plane, palm in picture plane, side from thumb, palm from fingers, palm from wrist, and side from little finger. 


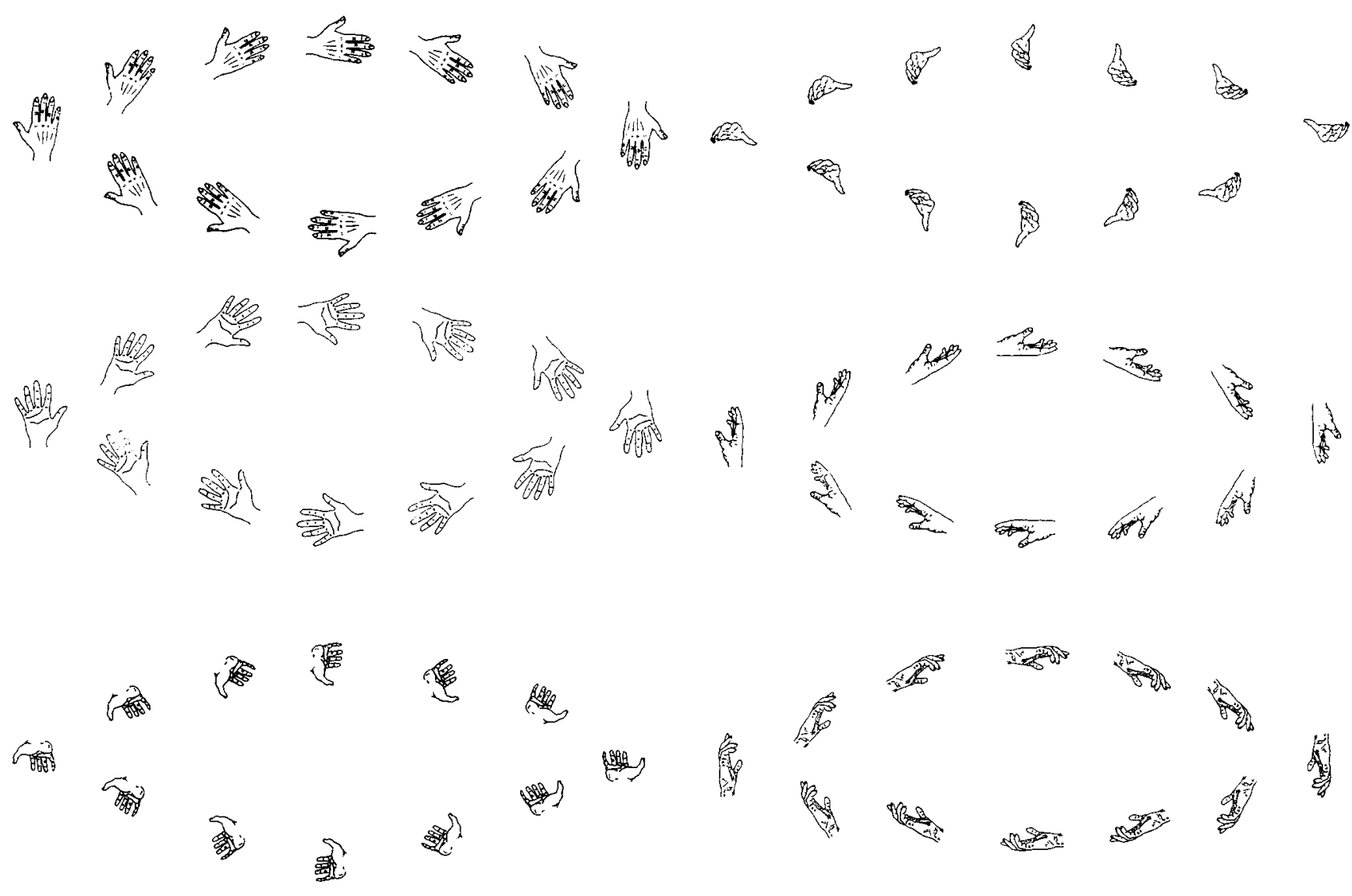

Figure 2. Each right hand stimulus view at lateral orientations (the upper elliptical series), at medial postures (the lower elliptical series), and the endpoint postures of $0^{\circ}$ and $180^{\circ}$ orientations, which are neither medial nor lateral.

their hands from its initial resting position into the position in the stimulus. Subjects were instructed to move their hands in a natural and efficient manner into the orientation of the stimulus. During a trial, subjects were free to view the target stimulus and their body as they wished. Prior to a set of trials, each subject was told whether stimuli were left or right hands. Subjects pressed the floor switch just as their hand reached the position and orientation of the stimulus. A stimulus was presented until a floor switch was pressed. Subjects were instructed not to make any head movements. An experimenter behind the subject provided feedback regarding the accuracy of the initial and final posture of the subject's hand on each trial; nearly all such correction occurred on practice trials.

During the left-right judgment task, the physical arrangement of subjects and apparatus was identical except that the subjects' left foot was on the leftmost floor switch and their right foot was on the rightmost floor switch. Subjects pressed the left switch for a left stimulus and the right switch for a right one. They responded as rapidly and accurately as they could but were not told how to make a judgment.

A $386,25-\mathrm{MHz}$ computer controlled the slide projectors and shutters and recorded response time (RT) and accuracy (of leftright judgments).

\section{Results}

Lateral and medial postures of the hand. In general, the length of the trajectory to move the hand from its current orientation to an orientation in which it faces the body's midsaggital plane (termed medial) is shorter than for orientations in which the hand is facing away from the body's midsaggital plane (termed lateral; Parsons, 1987b). (See Figure 2.) These different trajectory lengths are consequences of intrinsic joint constraints in the arm and hand. To analyze this critical effect of medial-lateral orientation, $0^{\circ}$ and $180^{\circ}$ trials are not included in analyses of variance (ANOVAs) because the stimuli are at neither medial nor lateral postures.

Real movement. An ANOVA of movement time using stimulus view (Figure 1), picture plane orientation $\left(30^{\circ}\right.$ to $150^{\circ}$ ), lateral-medial orientation (Figure 2), and hand (left or right) indicated the following effects predicted from Parsons's (1987b) analysis of joint constraints and reflected in Figure 3. Movement time was longer for lateral orientations where joint limits force longer trajectories, $F(1,19)=$ 
68.14, $p<.001, M S_{\mathrm{e}}=387,649$. Movement time was also longer for left-hand targets than right-hand targets, $F(1$, 19) $=5.91, p<.05, M S_{\mathrm{e}}=280,953$. This is to be expected because most of the subjects were probably right-handed, given the characteristics of the population (the handedness of subjects was not evaluated), and the time for movement of the nondominant hand is often observed to be slower than that for dominant hand. Furthermore, RT varied with orientation and stimulus view such that it increased as the target posture was more distant in the space of possible trajectories from the initial position of a subject's hand and arm, $F(4.76)=55.13, p<.001, M S_{\mathrm{e}}=129,211$, and $F(5$, $95)=52.78, p<.001, M S_{\mathrm{e}}=253,288$, respectively.

Several other interactions were caused by some combination of these effects of longer joint-constrained trajectories for lateral target postures, of dominant hand skill-speed advantage, and the distance in the space of possible trajectories between initial and target postures. The effect of picture plane orientation varied for lateral and medial orientations. $F(4,76)=10.78, p<.001, M S_{\mathrm{e}}=95,604$; the effect of orientation on movement time varied with stimulus view, $F(20,380)=12.72, p<.001, M S_{\mathrm{e}}=111,484$; the difference between medial and lateral orientations depended on stimulus view, $F(5,95)=21.71, p<.001, M S_{\mathrm{e}}=$ 194,333; and the difference between medial and lateral orientations was greater for the left hand than for the right hand, $F(1,19)=5.29, p<.05, M S_{\mathrm{e}}=115,559$. Lastly, the effect of picture plane orientation and lateral-medial orientation on movement time depended on stimulus view, $F(20$, $380)=11.59, p<.001, M S_{\mathrm{e}}=92,424$; and the effect of stimulus view and lateral-medial orientation on movement time depended on hand, $F(5,95)=2.35, p<.05, M S_{\mathrm{e}}=$ 63,670 .

Left-right judgment. Left-right judgment times were well correlated ( $r=.87$ ) with those of subjects in Parsons's (1987b) study who only made left-right judgments on these stimuli, $F(1,70)=212.90, p<.0001$. Left-right judgment times were unaffected by subjects first performing real movement to stimuli. The error rates were less than $5 \%$, ranging between $4.8 \%$ and $1.6 \%$, and were correlated with $\mathrm{RT}, r=.73, \mathrm{~B}(\mathrm{~F})(1,70)=80.22, p<.0001$. Trials on which subjects made errors were repeated later; RT data for correct trials only were included in other analyses.

An ANOVA of left-right judgment time using stimulus view, picture plane orientation, lateral-medial orientation, and hand indicated the following effects similar to those in Parsons's (1987b) studies. The effects are also similar to those for real movement times and likewise appear to reflect the influence of the factors of longer joint-constrained trajectories for lateral target postures, the distance in the space of possible trajectories between the initial and the target postures, and dominant hand skill-speed advantage.

Left-right judgment time was longer for lateral orientations where joint limits force longer trajectories and longer for left-hand targets than for right-hand targets, $F(1,19)=$ $95.21, p<.001, M S_{\mathrm{e}}=648,479$, and $F(1,19)=12.77$, $p<.01, M S_{\mathrm{e}}=563,500$, respectively. Furthermore, RT varied with orientation and stimulus view such that it increased as the target posture was more distant in the space of possible trajectories from the initial position of a subject's hand and arm, $F(4,76)=18.11, p<.001, M S_{\mathrm{e}}=$ 325,454 , and $F(5,95)=24.08, p<.001, M S_{\mathrm{e}}=1,624,061$.

The several other interactions were caused by some combination of these effects of longer joint-constrained trajectories for lateral target postures, of dominant hand skillspeed advantage, and the distance in the space of possible trajectories between initial and target postures. The effect of picture plane orientation varied with lateral and medial orientations, $F(4,76)=7.02, p<.001, M S_{\mathrm{e}}=268,451$; the effect of orientation on movement time depended on stimulus view, $F(20,380)=12.85, p<.001, M S_{\mathrm{e}}=285,037$; the difference between medial and lateral orientations depended on stimulus view, $F(5,95)=8.48, p<.001, M S_{\mathrm{e}}=$ 986,921; and difference between time for different stimulus views was greater for left hands than for right hands, $F(5$, 95) $=2.34, p<.05, M S_{\mathrm{e}}=226,175$. Lastly, the effect of picture plane orientation and lateral-medial orientation on movement time depended on stimulus view, $F(20,380)=$ $5.56, p<.001, M S_{\mathrm{e}}=289,451$.

Comparison of movement times and left-right judgment times. Time to move one's hand to the orientation and position in a stimulus (without making a left-right judgment) was very similar to the time to make a left-right judgment of the corresponding stimulus hand (see Figure 3). Over all stimuli, the correlation between movement and left-right judgment times was $.90-F(1,70)=298.40, p<$ .0001 -improving to $.95(p<.0001)$ when the very variable data for side from little finger were excluded. Overall mean movement time for each stimulus view (collapsing across orientation and hand) was strongly correlated ( $r=$ $.98, p<.001$ ) with that for left-right judgments. The correlation between time for movement (with no left-right judgment) and time for left-right judgment varied for different hand postures: for four stimuli, it was between .97 and .89; for the palm from fingers and side from little finger stimuli, it was .78 and .19 .

Movement RTs and left-right judgment RTs were nearly equivalent for the less awkward and more common hand orientations (i.e., the faster half of each function in Figure 3). However, left-right judgment times frequently exceeded the movement time for the more awkward and less common orientations (i.e., the slower half of each function in Figure 3). "Awkward" orientations are those that, because of joint constraints, require longer paths, activity at more joints, and more uncomfortable motion (Parsons, 1987b). Time for left-right judgments were longer than corresponding real movements (or mentally simulated movements; see Experiment 2), because in addition to the time required to mentally simulate the appropriate hand motion, time was required to make a left-right judgment.

\section{Discussion}

These data indicate that the time to move one's hand into the orientation depicted in the stimuli used in Parsons's (1987b) studies varies considerably. More important, the movement time (without making a left-right judgment) is 

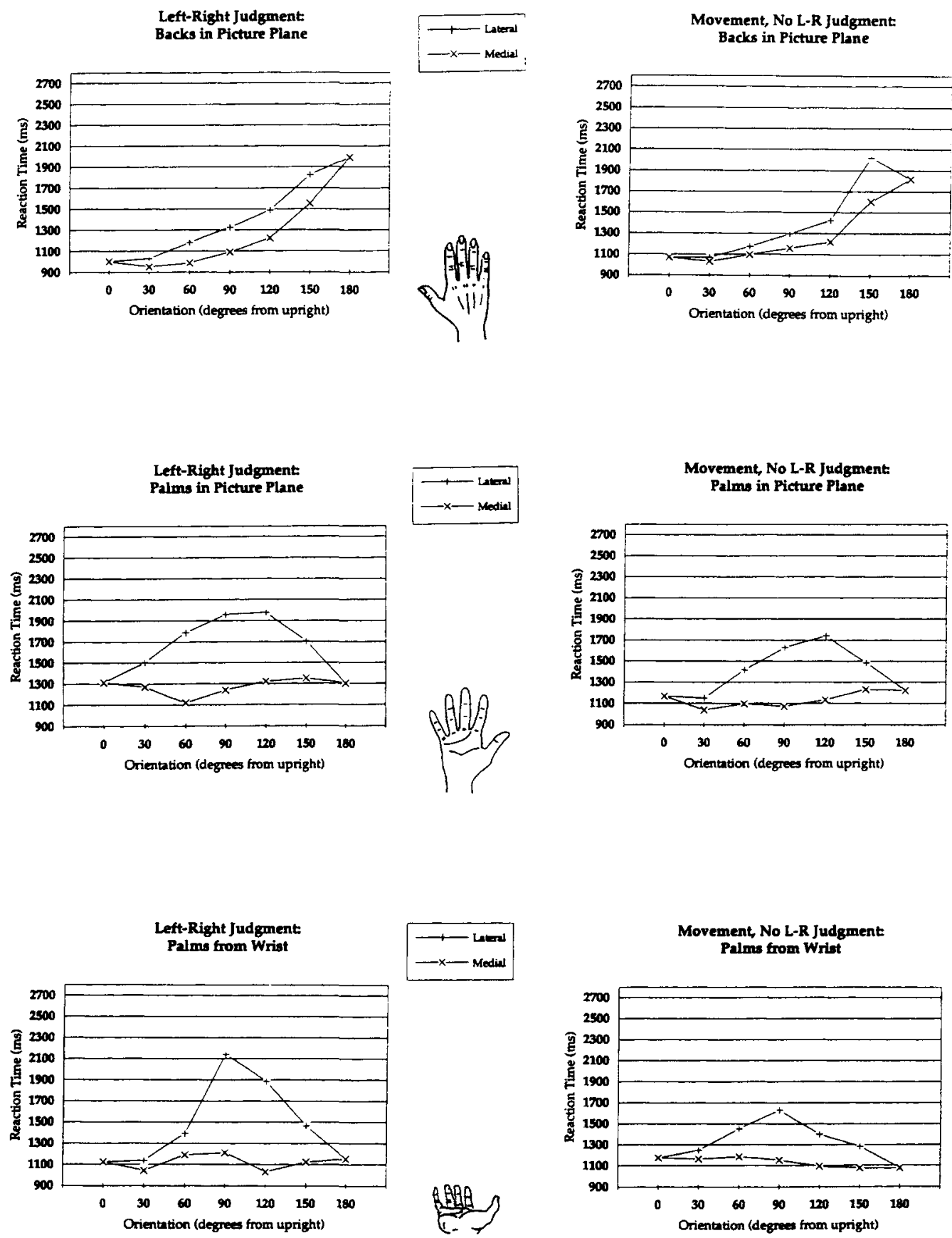

Figure 3. Reaction time-orientation functions for corresponding stimuli for left-right (L-R) judgments and of real movements.

well correlated with the ratings by Parsons's (1987b) subjects of the awkwardness of those movements, $r=.87, F(1$, $70)=218.30, p<.001$, and is highly correlated with the time for the current subjects to make a left-right judgment of the hand at corresponding orientations. As discussed earlier, previous studies indicated that subjects make leftright judgments by mentally simulating the movement of their own hands into the orientation of the stimulus for comparison. This process of mentally simulating one's movement into the orientation of a stimulus - prior to the conscious comparison of shape-probably caused left-right judgment times to parallel the movement times. This hypothesis was tested in Experiment 2, in which the time for subjects to move one of their hands into the orientation of a stimulus was compared to the time for them to mentally simulate that action. 

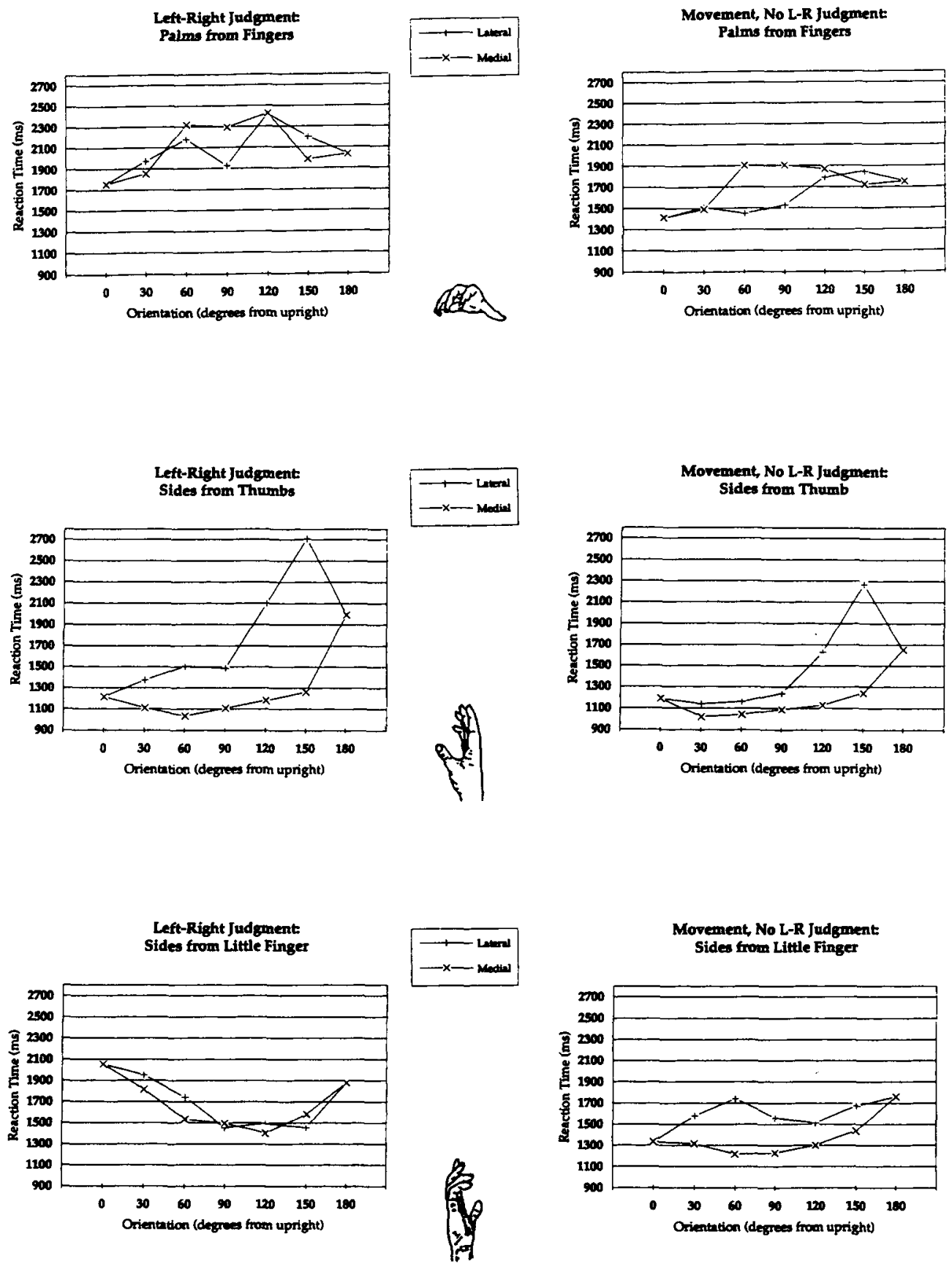

Figure 3, continued.

Experiment 2: Time for Mentally Simulated Movement Mimics Time for Real Movement

\section{Method}

Subjects. Twenty University of Texas at Austin undergraduates who had not been in any related studies volunteered to participate. Stimuli, design, and procedure. All aspects of the stimuli were identical to Experiment 1. Each subject was tested individually. Subjects performed three replications of the unique 144 real move- ment trials and three replications of the 144 imagined movement trials; the first replication in each condition was practice. All trials were blocked so that a set of 72 left-hand stimuli alternated with a set of 72 right ones. Within blocks, the view and orientation of stimuli were equally represented and in a subject-unique random order. Half of the subjects performed the real movement trials before the imagined movement ones; the others did the reverse.

The procedure for real movement was identical to that in Experiment 1 . During imagined movement, all aspects of the subject's body and apparatus were identical to that in real movement. 

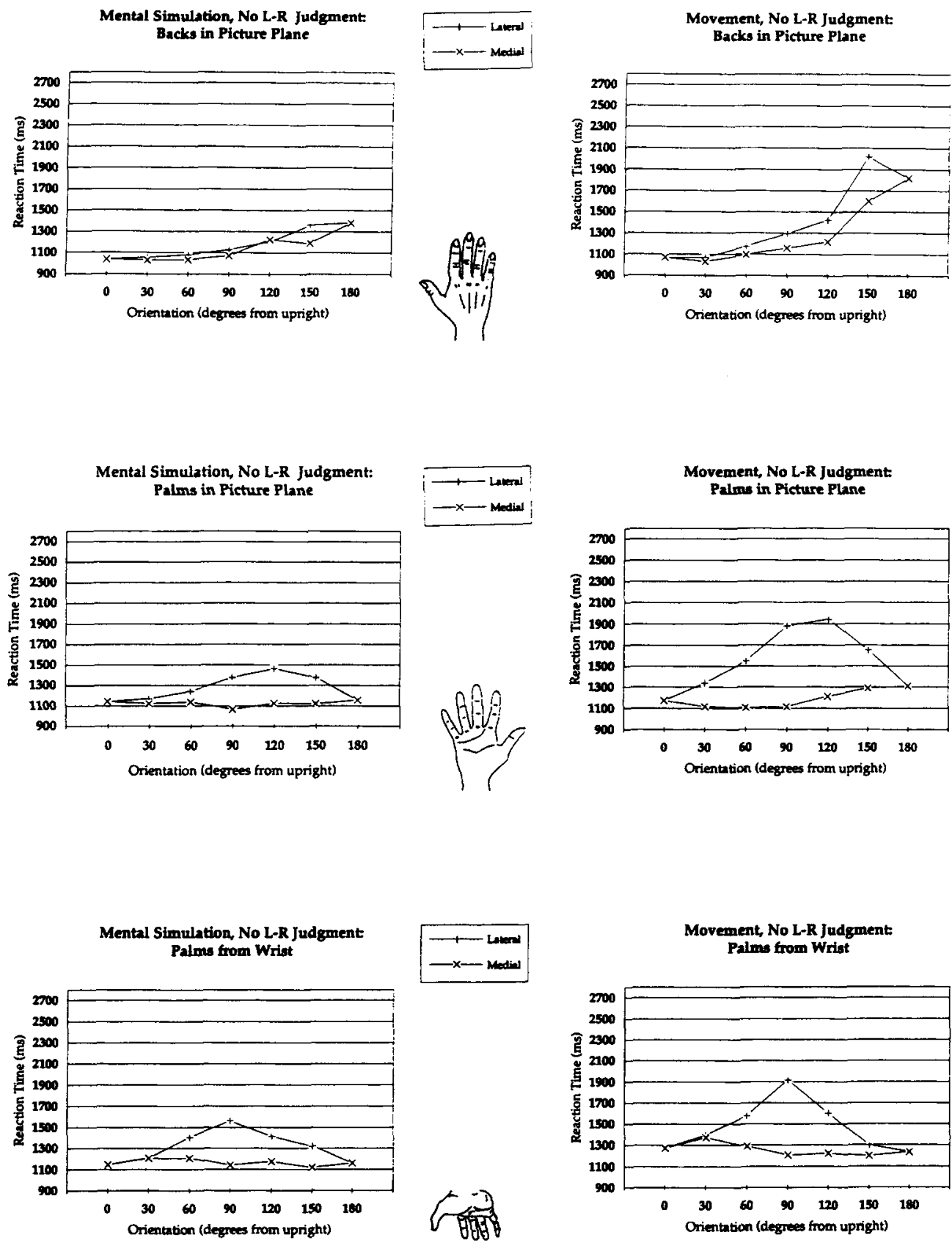

Figure 4. Reaction time-orientation functions of mentally simulated movement and of real movement into corresponding target postures. $L=$ left; $R=$ right.

However, subjects did not actually move their bodies at all, but rather vividly imagined moving their hands in a "natural and efficient" way from their current posture into that of the stimuli. Subjects pressed the floor switch as soon as they completed their imagined action. They were instructed not to make any head movements. During a session, an experimenter sat behind the subject to provide feedback as to the accuracy of the initial and final posture of the subject's hand on each trial (in real movement) and to insure that no real movement occurred (during imagined movement).

\section{Results}

Times for real movement. Movement times replicated those in Experiment 1 where subjects performed the real movement task first, $r=.95, F(1,70)=700.67, p<.0001$. 

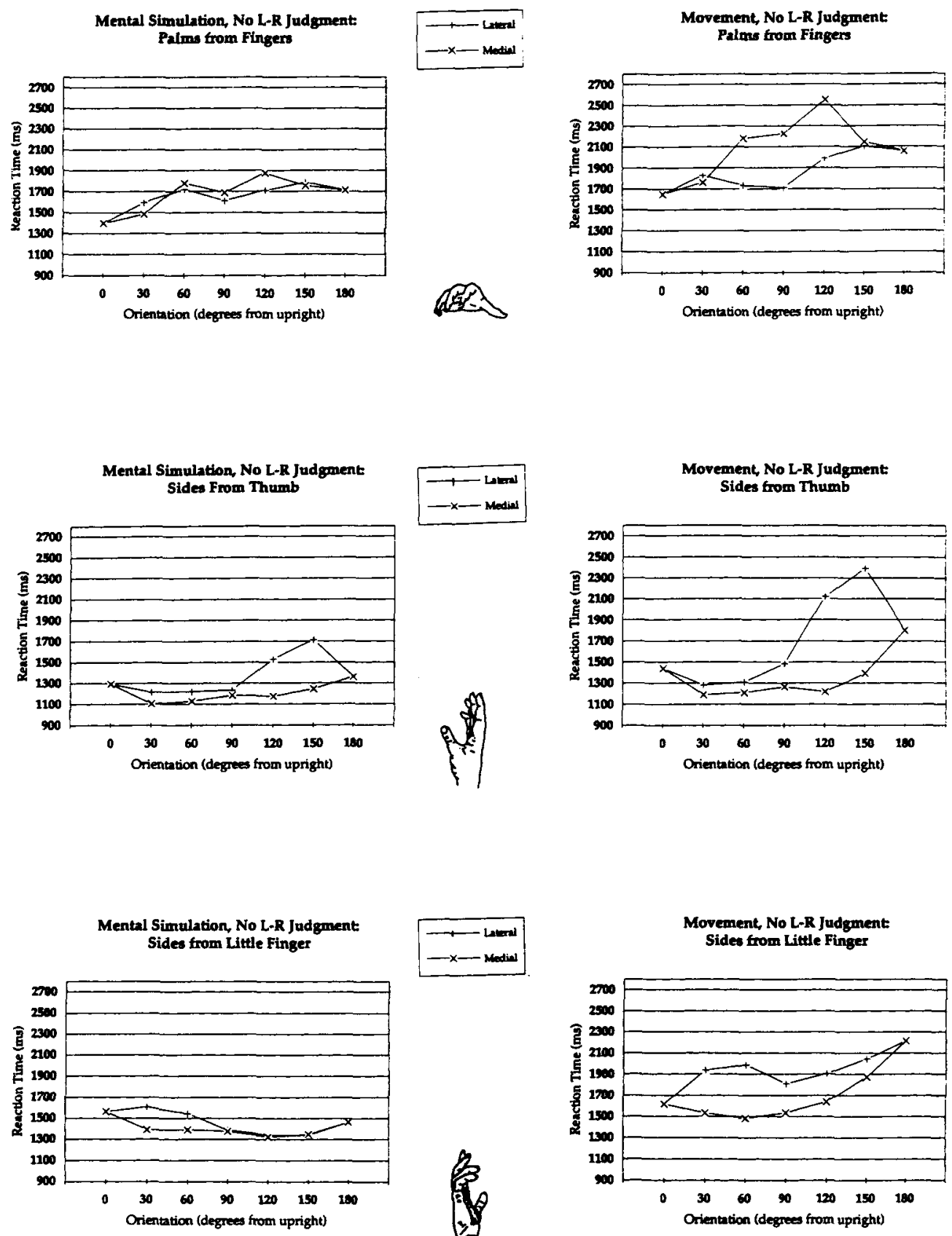

Figure 4, continued.

An ANOVA of movement time indicated a set of effects comparable with that discussed in Experiment 1 and caused by some combination of these effects of longer joint-constrained trajectories for lateral target postures, dominant hand skill-speed advantage, and the distance in the space of possible trajectories between initial and target postures. Movement time was longer for lateral orientations, $F(1$, $19)=57.15, p<.001, M S_{\mathrm{e}}=647,181$, and varied with orientation, $F(4,76)=52.33, p<.001, M S_{\mathrm{e}}=189,453$, and stimulus view, $F(5,95)=35.94, p<.001, M S_{\mathrm{e}}=$
815,396 . The effect of picture plane orientation varied for lateral and medial orientations, $F(4,76)=6.84, p<.001$, $M S_{\mathrm{e}}=154,837$; the effect of orientation on movement time depended on stimulus view, $F(20,380)=11.84, p<.001$, $M S_{\mathrm{e}}=160,812$; and the difference between medial and lateral orientations varied with stimulus view, $F(5,95)=$ 25.01, $p<.001, M S_{\mathrm{e}}=342,262$. Finally, the effect of picture plane orientation and lateral and medial orientation on movement time depended on stimulus view, $F(20$, $380)=12.30, p<.001, M S_{\mathrm{e}}=129,023$ 
Times for mentally simulated movement. An ANOVA of times for mentally simulated movement showed effects similar to those for real movement times and again reflected the effects of longer joint-constrained trajectories for lateral target postures, dominant hand skill-speed advantage, and the distance in the space of possible trajectories between initial and target postures. Time to imagine movements was longer for lateral orientations than for medial orientations, $F(1,19)=25.16, p<.001, M S_{\mathrm{e}}=355,965$, and longer for left hands than for right hands, $F(1,19)=21.27, p<.001$, $M S_{\mathrm{e}}=94,023$, and varied with orientation and stimulus view, $F(4,76)=8.29, p<.001, M S_{\mathrm{e}}=152,750$, and $F(5$, $95)=12.03, p<.001, M S_{\mathrm{e}}=1,292,936$, respectively. The effect of picture plane orientation on imagined movement time depended on stimulus view, $F(20,380)=4.48, p<$ $.001, M S_{\mathrm{e}}=127,573$; the difference between medial and lateral orientations varied with stimulus view, $F(5,95)=$ $7.19, p<.001, M S_{\mathrm{e}}=166,421$. Variation in time with stimulus views was greater for left hands than for right hands, $F(5,95)=2.34, p<.05$; and there was a marginal Picture Plane Orientation $\times$ Lateral-Medial Orientation interaction, $F(4,76)=2.37, p<.06, M S_{\mathrm{e}}=106,139$. Lastly, the effect of picture plane orientation and lateral-medial orientation on movement time depended on stimulus view, $F(20,380)=3.27, p<.001, M S_{\mathrm{e}}=112,847$.

Comparison of times for real and mentally simulated movements. Time to move one's hand to the posture in a stimulus (without making a left-right judgment) was very similar to the time to imagine such a movement (Figure 4). Over all stimuli, the correlation between movement time and imagined movement time was $.90, F(1,70)=284.45$, $p<.0001$, improving to .93 when the side from little finger trials were excluded, $p<.0001$. There was a strong correlation $(.98, p<.001)$ between the overall mean real movement time and imagined movement time for each stimulus view (collapsing across orientation and hand). The correlation between time for real movement and time of imagined movement varied for different hand postures: for four stimuli, it was between .98 and .93 ; for the palm from fingers and side from little finger stimuli, it was .81 and .20 .

Real movement time and imagined movement time were nearly equivalent for the less awkward, more common hand orientations (i.e., the faster half of each function in Figure 4). In fact, for $0^{\circ}$ and the medial orientations from $30^{\circ}$ to $120^{\circ}$ for four stimuli, excluding palm from fingers and side from little finger, those times for real movement and simulated movement were not statistically different $(p>.05)$. However, movement time very often (considerably) exceeded the imagined movement time for the more awkward and less common orientations (i.e., the slower half of each function in Figure 4).

There were no effects of task order, $p>.05$; all other analyses were collapsed across order.

\section{Discussion}

The findings in Experiment 2 indicated that the times for mentally simulating movements of one's hand from a nat- ural resting posture into very many other postures are spontaneously highly correlated with the time to actually make such movements. For the less awkward and more familiar target hand postures (often in medial hand space), the time to imagine action and to perform action were usually equal. For the more awkward and less common target hand positions, the time for real movement was longer than, but generally proportional to, the time for imagined movement. Furthermore, the correlation between simulated and real movement time was weakest for the very most awkward and uncommon target hand postures (i.e., side from little finger and palm from fingers stimuli).

Further investigation will be necessary to clarify why the correspondence between temporal properties of real action and of mentally simulated action varied in this way for awkward uncommon target postures and for nonawkward common ones. One factor that may play a role in this phenomenon is that movement into the more awkward orientations requires changes at more than one joint and involves interactions among such changes (Soechting \& Lacquaniti, 1981). The complexity of such structural change may exceed the precision or capacity of the processes underlying mental simulations; as a consequence, such movement may be more crudely approximated, requiring proportionally less time than for the real action. A second possibility is that the mental simulation of movement into the less familiar target postures is based on less detailed information, and the default tendency is to produce rapid but sketchy simulations.

The striking correspondences observed here between the time for real movement and the time for mentally simulated movements were not likely caused by instruction artifact or demand characteristic. RT-orientation functions for mentally simulating motion without a left-right judgment are very highly correlated with those of other subjects making left-right judgments of these stimuli under instruction only to "decide the handedness of each stimulus" (Parsons, 1987b; Parsons, Gabrieli, \& Gazzaniga, 1993). These functions are characteristic of the spontaneous mental simulation of one's action. The times for real movements are very similar across groups of subjects and are unaffected by whether or not subjects first imagine those movements on instruction.

\section{Experiment 3: Alternative Measurements of Real Movement Time}

In this experiment, I assessed the effect of two potential sources of error in the measurement in Experiments 1 and 2 of the time for moving one's hand into the target posture of a stimulus. (1) Subjects may not be accurate in detecting and signaling exactly when their hand achieved the target posture. (2) The time to perceive the target stimulus likely varied, so that it was longer for unfamiliar and awkward orientations and shorter for familiar and nonawkward ones, and this variation was conflated with the time for actual movement. In Experiment 2, where the purpose was to compare the time to complete one's action and the time to complete mental simulations of those actions, (1) and (2) 
appeared equally true of each performance, making for appropriate comparisons. However, it would be useful in general to clarify the influence on RT patterns of these two potential effects. In Experiment 3, an experimenter who was blind to the experimental hypothesis and to the stimulus on each trial observed a subject's movement and pressed a response button when the movement was completed. Furthermore, in this experiment subjects viewed the stimulus depicting the target posture for $750 \mathrm{~ms}$ before initiating their action. During this instructed delay, the target was perceived and preparation of the ensuing motor response likely occurred. At the end of this delay, a tone was presented signaling the subject to initiate an appropriate movement (as in Experiments 1 and 2).

Because the time to perceive each target stimulus and the time to prepare movement into that posture are both excluded from the measured movement times here, I expected the movement times to be shorter than those in Experiment 1. Indeed, relative to the movement times in Experiment 1, the movement times here should be especially shorter for the unfamiliar and awkward target postures, such as those depicted by palms from fingers and sides from little fingers stimuli. However, if the patterns of movement times under these conditions were very similar to those in Experiments 1 and 2, it would indicate that the times recorded in Experiments 1,2 , and 5 accurately reflected variation in movement time to different target postures.

\section{Method}

Subjects. Eleven University of Texas at Austin undergraduates who had not been in any related studies volunteered to participate.

Stimuli, design, and procedure. With the following exceptions, all aspects of the stimuli, design, and procedure were identical to those in the real movement task in Experiment 1. An experimenter, blind to the experimental hypothesis, sat facing the subject away from the stimulus and pressed a floor switch after detecting the conclusion of a subject's hand and arm movement. Another experimenter observed the subject's movement and provided feedback as to the accuracy of the initial and final posture of a subject's hand. Furthermore, the stimulus was presented for $750 \mathrm{~ms}$, during which time the subject was instructed to prepare to move the hand to the posture of the stimulus. At the end of this $750-\mathrm{ms}$ period, a tone was presented to signal the subject to begin the movement.

\section{Results}

An ANOVA of movement time using stimulus view, picture plane orientation $\left(30^{\circ}\right.$ to $\left.150^{\circ}\right)$, lateral-medial orientation, and hand (left or right) indicated a set of effects similar to that in Experiments 1 and 2 for real movement times. Once again, the effects were caused by combinations of the factors of longer joint-constrained trajectories for lateral target postures, dominant hand skill-speed advantage, and the distance in the space of possible trajectories between initial and target postures (see Figure 5). Movement time was longer for lateral orientations than for medial orientations, $F(1,10)=16.45, p<.01, M S_{\mathrm{e}}=278,152$, and longer for left hands than for right hands, $F(1,10)=$ $18.64, p<.01, M S_{\mathrm{e}}=53,221$. Movement time varied with orientation and stimulus view, $F(4,40)=15.73, p<.001$, $M S_{\mathrm{e}}=80,255$, and $F(5,50)=13.82, p<.001, M S_{\mathrm{e}}=$ 139,714 , respectively. The effect of orientation on movement time depended on stimulus view, $F(20,200)=3.59$, $p<.001, M S_{\mathrm{e}}=90,279 ;$ and the difference between medial and lateral orientations varied with stimulus view, $F(5$, $50)=11.12, p<.001, M S_{\mathrm{e}}=121,532$. Finally, the effect of picture plane orientation and lateral and medial orientation on movement time depended on stimulus view, $F(20$, $200)=4.01, p<.001, M S_{\mathrm{e}}=77,411$.

When an experimenter observed a subject's hand movement and the time to perceive the target posture was factored out of RT, the time to move the hand to the posture in a stimulus (without making a left-right judgment) was very similar under the conditions in Experiment 1. The correlation between these movement times and those in Experiment 1 was $.95, F(1,70)=647.64, p<.0001$.

In addition, under these conditions subjects were about $300 \mathrm{~ms}$ faster over all stimuli than subjects whose RT included the time to perceive the target posture and the time to make their own assessment of the conclusion of their movement into the target. Relative to the latter subjects, the subjects here were about $450 \mathrm{~ms}$ faster for the palms from fingers stimuli and $350 \mathrm{~ms}$ faster for the sides from little fingers stimuli, but about $230 \mathrm{~ms}$ faster for the other stimulus views. These differences across conditions for different stimuli are consistent with the idea that the time to perceive the target posture is longer for unfamiliar and awkward postures.

\section{Discussion}

The results of Experiment 3 indicated that when an experimenter detected the completion of a subject's movement into target hand postures, the pattern of recorded movement times was very similar to that obtained when subjects themselves detected the completion of their movements. Furthermore, when the time to-perceive the target posture (which is apparently slower for unfamiliar orientations than familiar ones) was separated from the time for movement by having an instructed delay prior to movement, the pattern of recorded movement times was very similar to that pattern of RTs when processes of target perception and real movement were not separated.

\section{Experiments 4 and 5: The Represented Disposition of One's Body in Its Imagined Movement}

Subjects in Experiment 4 made a left-right judgment of a hand (as in Parsons, 1987b, and Experiment 1) but under conditions varying the orientation and body-relative posture of their hands. As shown in Experiments 1, 2, and 3, there were strong correlations among the times for real movement, for imagined movement without a left-right judgment, and for imagined movement during left-right judgments. If imagined movements during left-right judgments here originated at the different current actual hand positions, then the time for the left-right judgments should parallel 


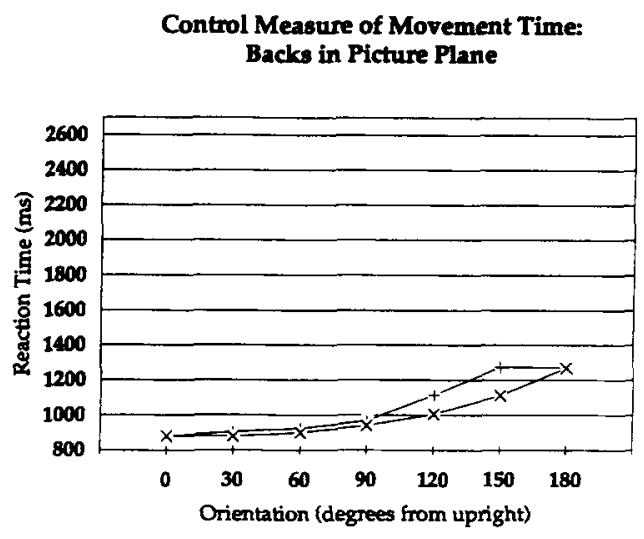

Control Measure of Movement Time: Palms in Picture Plane

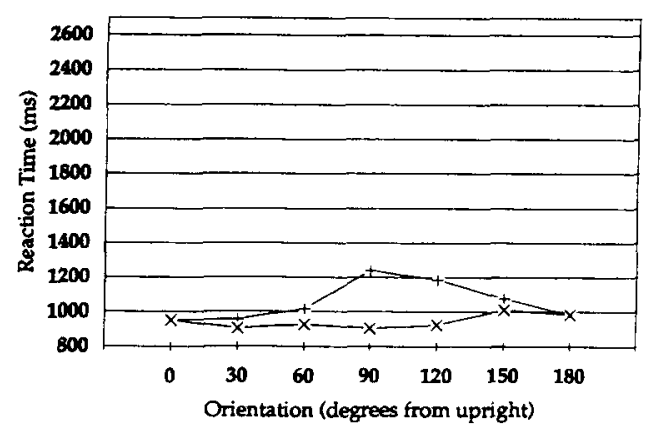

Control Measure of Movement Time: Palms from Wrist

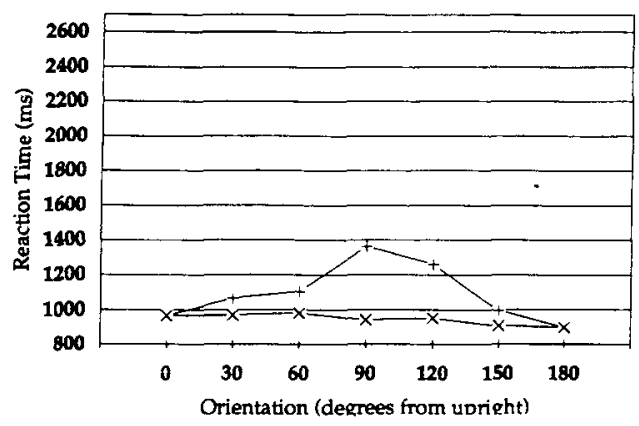

Control Measure of Movement Time: Palms from Finger
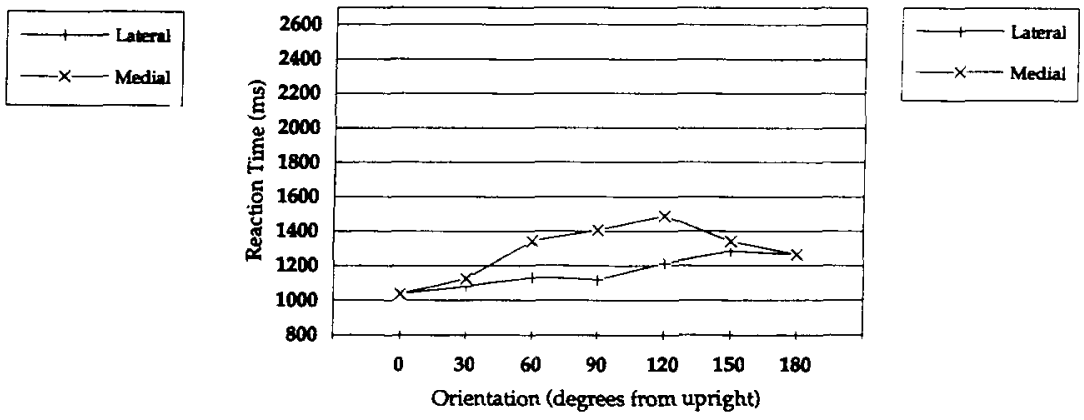

Control Measure of Movement Time: Sides from Thumb
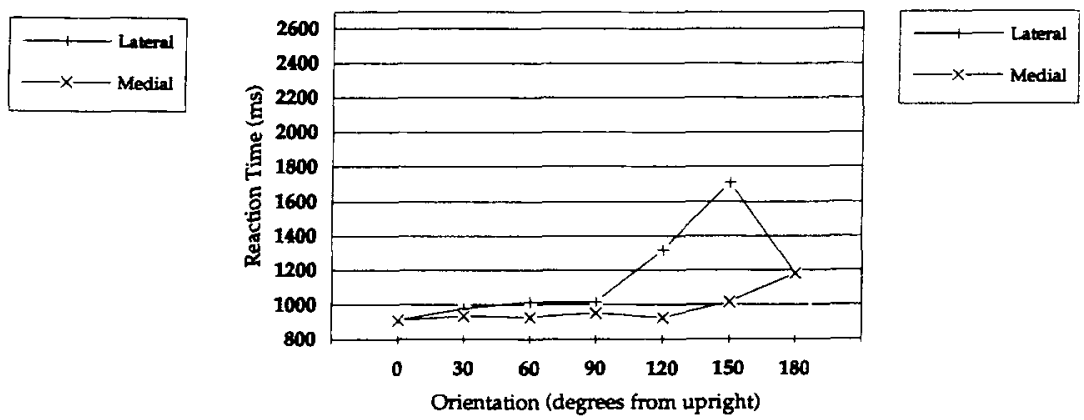

Control Measure of Movement Time: Sides from Little Finger
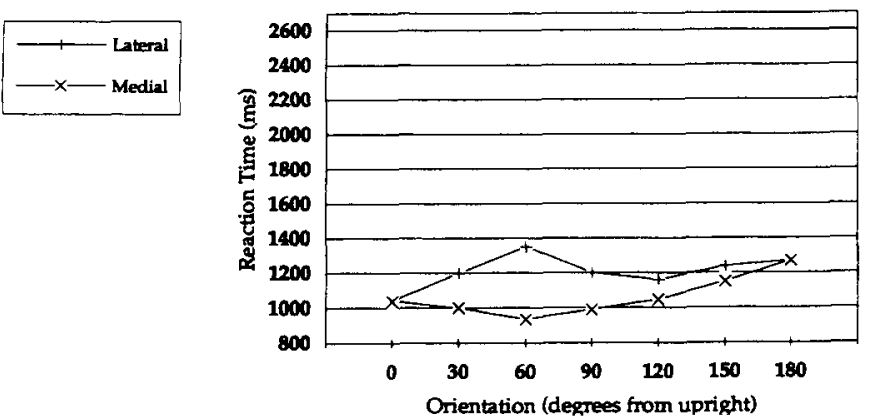

Figure 5. Reaction time (RT)-orientation functions for real movements when movement time is measured by experimenter and when time to perceive target is factored out of R'T.

corresponding real movement times. In Experiment 5, I observed the times for real movement into stimulus targets from current hand postures adopted by subjects in Experiment 4.

Movement time into different target postures was probably determined by enduring joint constraints on trajectory formation, and much less influenced by the posture from which motion originated, because movements of different extents tended to have the same duration (Viviani \& McCollum, 1983). Thus, RT-orientation functions for moving one's hand from different initial postures into postures in stimuli would probably be parallel but differ by a roughly constant time proportional to differences between trajectory lengths from the initial positions. The time for movement from the palms away posture should exceed the time for movement from the palms down posture because in the former the hand is at the extremes of its joint limit in one degree of movement freedom, whereas in the latter the hand is approximately equidistant from the extremes of its joint limits. 


\section{Experiment 4: Left-Right Judgment of a Hand With Observer's Body in Different Configurations}

\section{Method}

Subjects. Twenty-four University of Texas at Austin undergraduates who had not been in any related studies volunteered to participate.

Stimuli, design, and procedure. Subjects saw the drawings of left and right hands viewed from four of the perspectives in Figure 1: back in picture plane, palm in picture plane, side from little finger, and palm from wrist. Stimuli were the same as those used in Experiment 1.

Subjects performed a series of three replications of the unique 96 trials under each condition of real hand position. They also performed 48 practice trials with their hands in the down condition. Trials were randomly ordered for each subject. Trials on which subjects made errors were repeated later in a block.

Subjects sat before a screen on which stimuli were rearprojected, with each foot resting on a microswitch. They pressed the leftmost switch with the left foot for a left-hand stimulus and the rightmost switch with the right foot for a right-hand stimulus. Subjects' hands were covered with a black felt cloth and secured (with Velcro straps) in one of two positions: palms down, when the palms were flat on the table in front of them (as in Experiments 1 and 2); and palms away, when the hands were back to back, palms facing away from the midsagittal plane. All other aspects of the left-right judgment task were the same as in Experiment 1.

\section{Results}

Left-right judgment time depended on the observer's current hand position, as well as the orientation, view, and handedness of a stimulus (Figure 6). RT-orientation functions produced when subjects had their palms down replicated those of subjects in Parsons (1987b) and in Experiment 1. Generally parallel RT-orientation functions were produced when subjects' hands were in the away condition, but overall mean RT was $118 \mathrm{~ms}$ longer, $F(1,23)=4.01$, $p<.057, M S_{\mathrm{e}}=3,990,946$. In addition, an ANOVA of RT showed two interactions involving current hand position: $\mathrm{RT}$ varied with hand position and picture plane orientation of the stimulus, $F(8,184)=2.05, p<.05, M S_{\mathrm{e}}=464,443$; and it varied with hand position, stimulus view, picture plane orientation, hand, and lateral and medial orientation, $F(24,552)=1.66, p<.05, M S_{\mathrm{e}}=330,477$. The ANOVA of RT also showed effects comparable to those for RTs in the left-right judgment task in Parsons (1987b) and in Experiment 1, reflecting once again combinations of the factors of longer joint-constrained trajectories for lateral target postures, of dominant hand skill-speed advantage, and the distance in the space of possible trajectories between initial and target postures. Thus, RT was longer for lateral than for medial orientations, and for left hands than for right hands, $F(1,23)=22.44, p<.001, M S_{\mathrm{e}}=$ $5,007,953$, and $F(1,23)=11.97, p<.01, M S_{\mathrm{e}}=$ $1,360,459$, respectively. RT varied with orientation and stimulus views, $F(4,92)=17.19, p<.001, M S_{\mathrm{e}}=$ 712,445 , and $F(3,69)=20.43, p<.001, M S_{\mathrm{e}}=2,681,249$. The effect of picture plane orientation varied for lateral and medial orientations, $F(4,92)=6.85, p<.001, M S_{\mathrm{e}}=$ 704,867; the effect of picture plane orientation depended on stimulus view, $F(12,276)=10.54, p<.001, M S_{\mathrm{e}}=$ $1,231,006$; the difference between lateral and medial orientations varied with stimulus view, $F(3,69)=7.16, p<$ $.001, M S_{\mathrm{e}}=2,665,378$. Also, the combined effect of picture plane orientation and lateral-medial orientation on movement time depended on stimulus view, $F(12,276)=4.69$, $p<.001, M S_{\mathrm{e}}=601,510$.

Subjects' error rates were less than $5 \%$ (range $=4.9 \%$ to $2.1 \%$ ); error rates did not differ for the two conditions of current hand posture.

The greatest effect of current real hand position was for palms in picture plane stimuli: on average, RTs were $220 \mathrm{~ms}$ longer in the away condition than in the down position. An ANOVA on the RTs for this stimulus showed that this difference is significant, $F(1,23)=8.42, p<.008, M S_{\mathrm{e}}=$ $1,624,081$. On the basis of preceding results, this extra RT probably was caused by the additional trajectory length required to mentally simulate moving one's hand from its current posture into the stimulus posture. For example, to turn physically the hand from the away condition posture to the palm in picture plane at $0^{\circ}$ required about $270^{\circ}, 90^{\circ}$ more than to turn the hand from the down condition posture into the stimulus orientation. Mentally simulating such a $90^{\circ}$ turm appears to require about $200 \mathrm{~ms}$, as suggested by the RT function for the back of the hand in the down condition (the RT for $90^{\circ}$ is $200 \mathrm{~ms}$ longer than that for $0^{\circ}$ ). These interpretations appeared to be confirmed in Experiment 4.

\section{Discussion}

The findings in Experiment 4 showed that the current origin of one's body influenced the time to make a left-right judgment of a body part. As predicted, the time to make left-right judgments of hands when one's arms and hand are in the palms away posture was often parallel but greater than the left-right judgment time when one's arms and hands are in the palms down posture. Given the findings discussed in the introduction, this is likely to occur because the spatial origin from which one spontaneously imagines a spatial transformation of one's body is its current orientation, not a fixed canonical one. In Experiment 5, I evaluated this hypothesis by observing the times for real movement into the stimulus postures from current hand postures adopted by subjects in Experiment 4.

\section{Experiment 5: Time for Moving One's Hand From Different Initial Postures Into Target Postures in Stimuli}

\section{Method}

Subjects. Fifteen University of Texas at Austin undergraduates who had not been in any related study volunteered to participate.

Stimuli, design, and procedure. All aspects of the stimulus and design were identical to those in Experiment 4, except that trials 
L-R Judgment: Backs in Picture Plane Two Different Subject Hand Positions
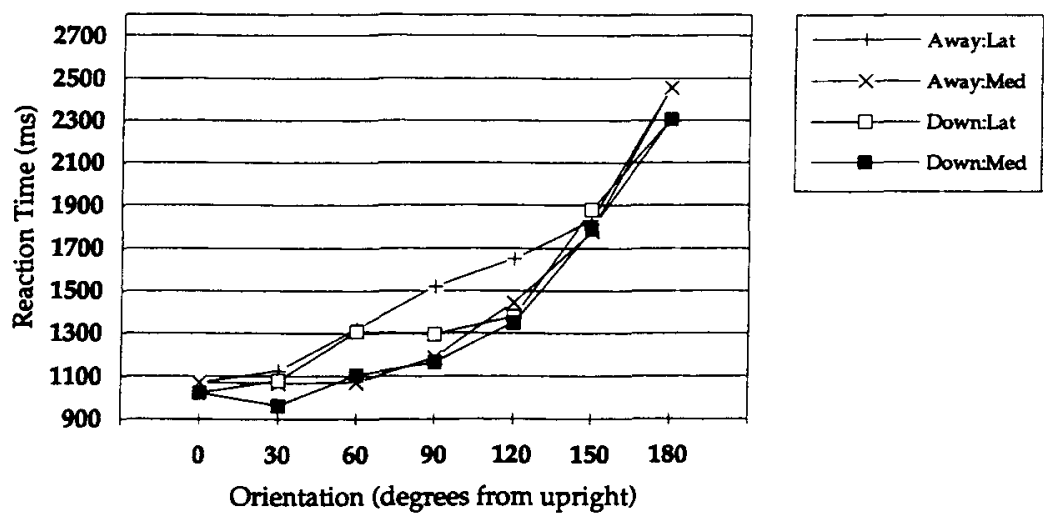

L-R Judgment: Palm in Picture Plane Two Different Subject Hand Positions
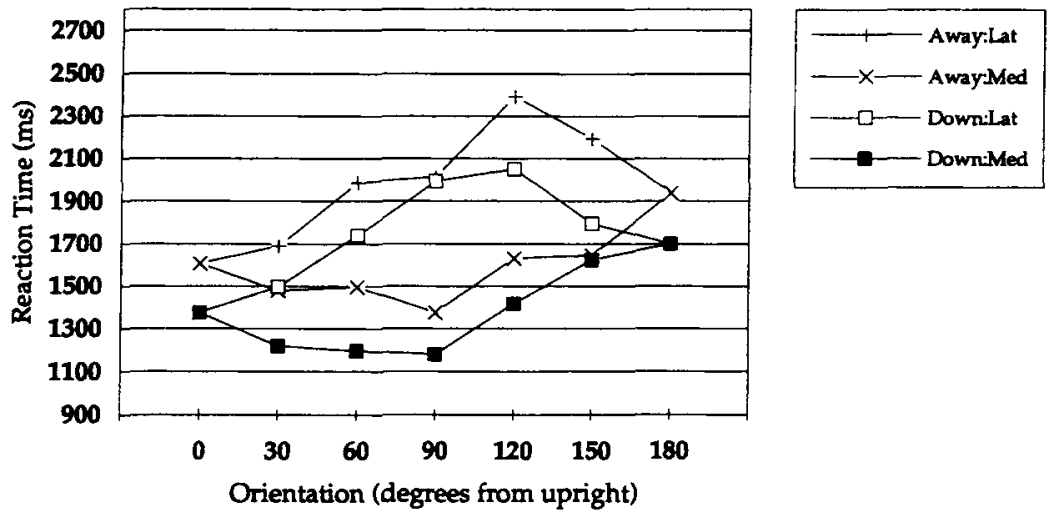

Figure 6. Reaction time-orientation functions of left-right (L-R) judgments when observers' hands are in the palms away posture and the palms down posture.

were blocked so that a set of 48 left-hand stimuli alternated with a set of 48 right-hand stimuli. Within these blocks, the view and orientation of stimuli were equally represented and in a random order unique for each subject and block. Half of the subjects performed three replications with the movement starting from the palms down posture first and then performed three replications with the movement starting from the palms away posture; the other subjects performed the conditions in reverse order. The procedure was identical to the real movement conditions in Experiments 1 and 2, except that at the start of each trial a subject's hands rested palms down (or palms away), as in Experiment 4.

\section{Results}

Real movement from different initial postures. The movement time functions in Figure 6 for the palms down position were very highly correlated $(r=.97)$ with those of subjects in Experiment 1 where the same stimuli, hand position, and task were used, $F(1,46)=625.56, p<.0001$.

There was no difference in the time for left-hand and right-hand movements from the palms down posture $(1,349$ $\mathrm{ms}$ and 1,351 ms), although there was one in movement times in Experiments 1 and 2. There was also no RT difference for left- and right-hand movement from the palms away posture. This suggests that there was an approximately equal mix of left-handed and right-handed subjects in this study.

An ANOVA of movement time showed a set of effects comparable to those for movement time tasks in Experiments 1 and 2, reflecting the combination of the factors of longer joint-constrained trajectories for lateral target postures, the distance in the space of possible trajectories between initial and target postures, and, to a lesser extent, of 
L-R Judgment: Palm from Wrist Two Different Subject Hand Positions

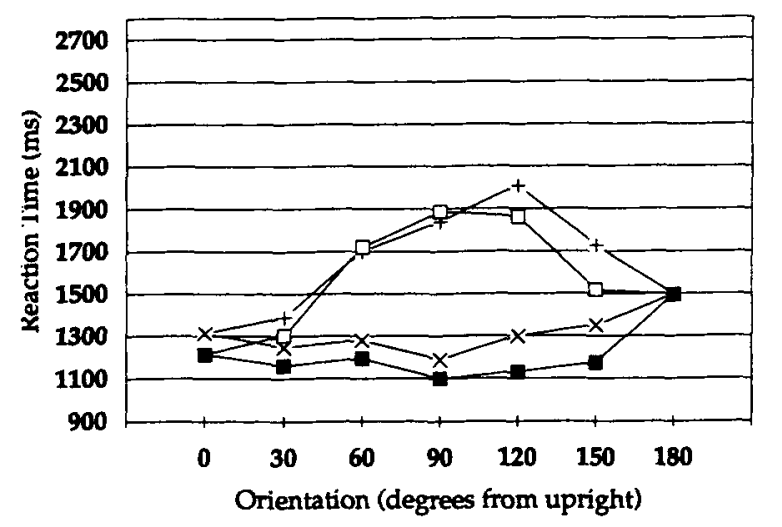

L-R Judgment: Sides from Little Finger Two Different Subject Hand Positions
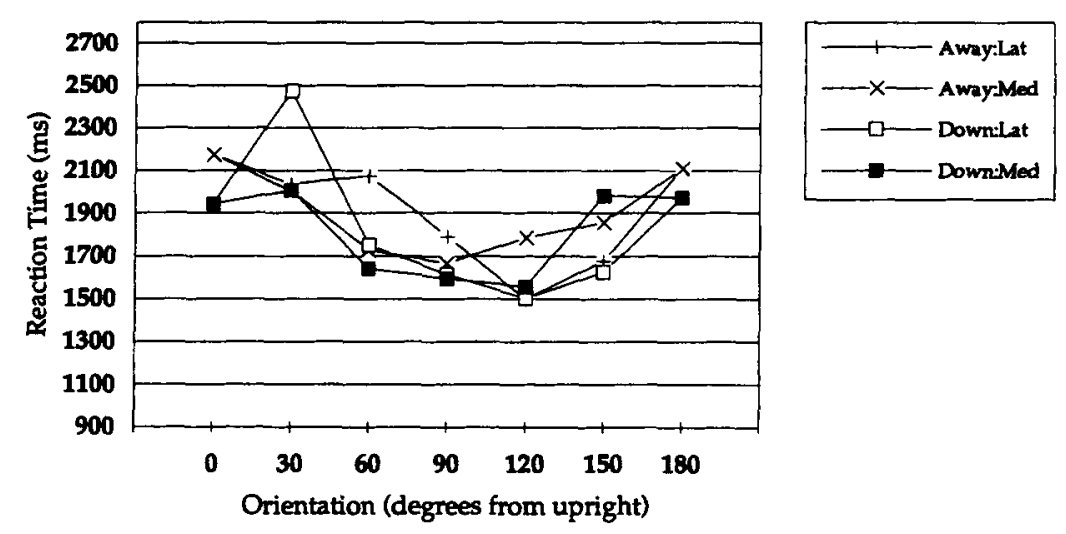

Figure 6, continued.

dominant hand skill-speed advantage. Movement time was longer for lateral than for medial orientations, $F(1,14)=$ $188.74, p<.001, M S_{\mathrm{e}}=300,491$, and varied with orientations and stimulus view, $F(4,56)=42.85, p<.001$, $M S_{\mathrm{e}}=118,765$, and $F(3,42)=37.70, p<.001, M S_{\mathrm{e}}=$ 272,848 , respectively. The effect of picture plane orientation was different for lateral and medial orientations, $F(4$, $56)=15.75, p<.001, M S_{\mathrm{e}}=79,445$; the effect of orientation on movement time varied with stimulus view, $F(12,168)=27.44, p<.001, M S_{\mathrm{e}}=84,601 ;$ the difference between medial and lateral orientations depended on stimulus view, $F(3,42)=12.59, p<.001, M S_{\mathrm{e}}=89,473$; and the effect of picture plane orientation on movement time varied with hand, $F(4,56)=5.18, p<.001, M S_{\mathrm{e}}=51,534$. The combined effect of picture plane orientation and lateral-medial orientation on movement time depended on stimulus view, $F(12,168)=14.54, p<.001, M S_{\mathrm{e}}=$
83,032 ; the effect of picture plane orientation and stimulus view varied with hand, $F(12,168)=2.24, p<.05, M S_{\mathrm{e}}=$ 57,713; and Stimulus View $\times$ Picture Plane Orientation $\times$ Lateral-Medial Orientation $\times$ Hand interaction, $F(12$, $168)=1.98, p<.05, M S_{\mathrm{e}}=54,313$.

In addition, this ANOVA revealed effects involving the initial posture of the hand: Movement time was longer for palms away posture than for palms down posture, $F(1$, $14)=6.29, p<.05, M S_{\mathrm{e}}=1,390,991$, and the effect of picture plane orientation and the stimulus view depended on initial hand posture, $F(12,168)=1.83, p<.05, M S_{\mathrm{e}}=$ 52,200 . There was an interaction among initial hand posture, stimulus view, picture plane orientation, and lateralmedial orientation, $F(12,168)=2.39, p<.01, M S_{\mathrm{e}}=$ 50,731 .

Comparison of movement times in Experiment 5 and left-right judgment times in Experiment 4. Time to move 


\section{Movement RT for Different Hand Position} Backs in Picture Plane
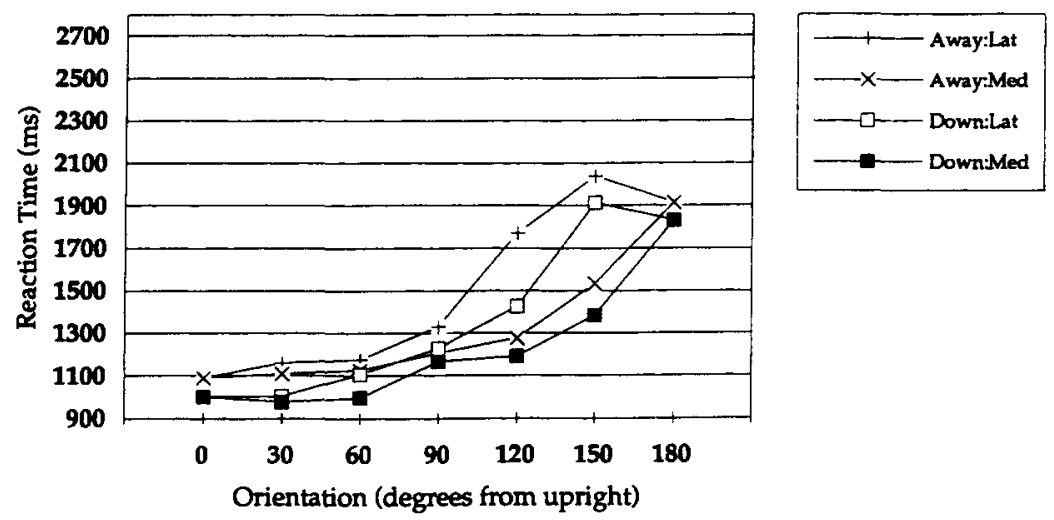

\section{Movement RT for Different Hand Position Palms in Picture Plane}
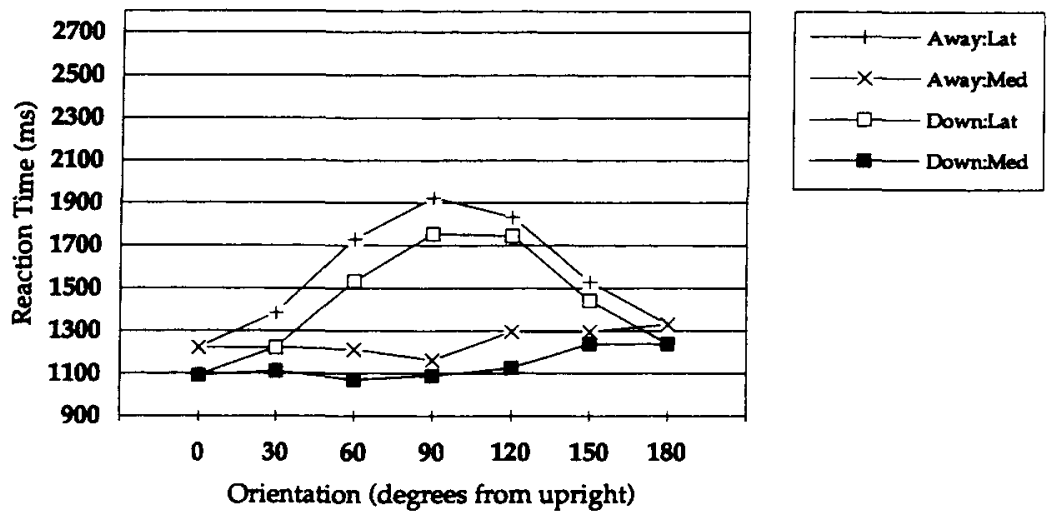

Figure 7. Reaction time-orientation functions for real movement from the palms away posture and the palms down posture into target postures.

one's hand from the palms down and palms away postures into a stimulus orientation (without making a left-right judgment) was similar to the time to make a left-right judgment of that stimulus when one's hand was in the palms down and palms away positions and imagined movement occurred. Exactly as with left-right judgment times, there were roughly parallel movement RT-orientation functions from the palms away and palms down postures (Figure 7), with the palms away conditions $120 \mathrm{~ms}$ longer overall, $F(1$, 14) $=6.16, p<.05, M S_{\mathrm{e}}=1,685,926$. There was a strong correlation $(r=.80)$ between movement time (with no left-right judgment) and left-right judgment time for the palms down and palms away conditions over all stimuli, $F(1,94)=169.94, p<.0001$, improving to $r=.86$ if, as in Experiments 1 and 2, the variable data for side from little finger were excluded, $F(1,70)=195.94, p<.0001$. There was also a strong correlation $(r=.86)$ between the overall mean RT to each stimulus for movement and left-right judgment tasks, $F(1,6)=17.24, p<.01$. Collapsing across orientation and hand, the correlation between time for movement and left-right judgment was between .89 and .87 for three stimuli and .22 for side from little finger stimuli.

\section{Discussion}

The interlocking results of Experiments 4 and 5 indicate that the spatial origin from which one spontaneously imagines a spatial transformation of one's body is its current orientation, not a fixed canonical one, and that the representation of the arm and hand used in the mental simulations is based on nonvisual information that is mapped onto the visual target stimulus. These findings confirm for another set of motions that time for mentally simulating actions 
Movement RT for Different Hand Position

Palms from Wrist
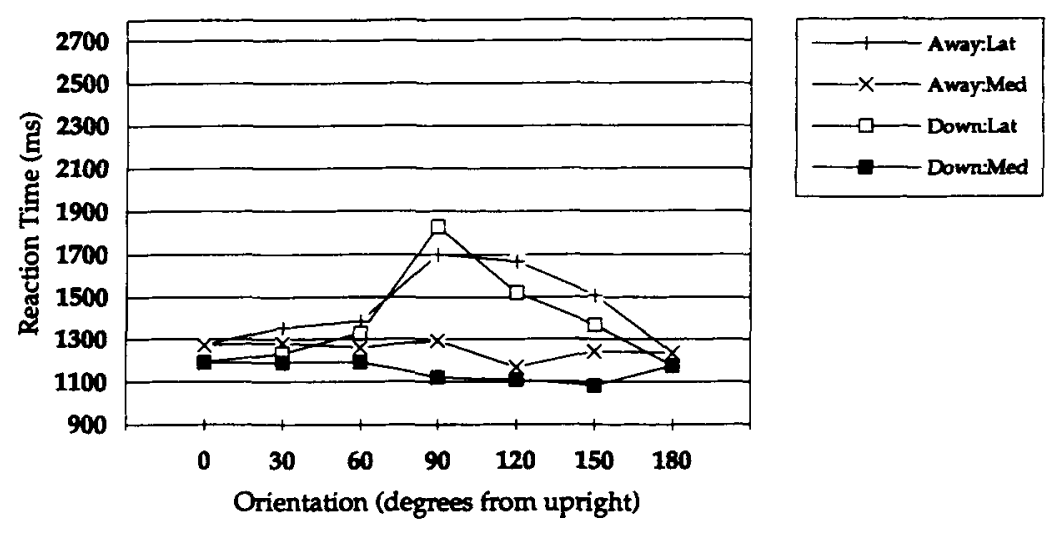

Movement RT for Different Hand Position Sides from Little Finger
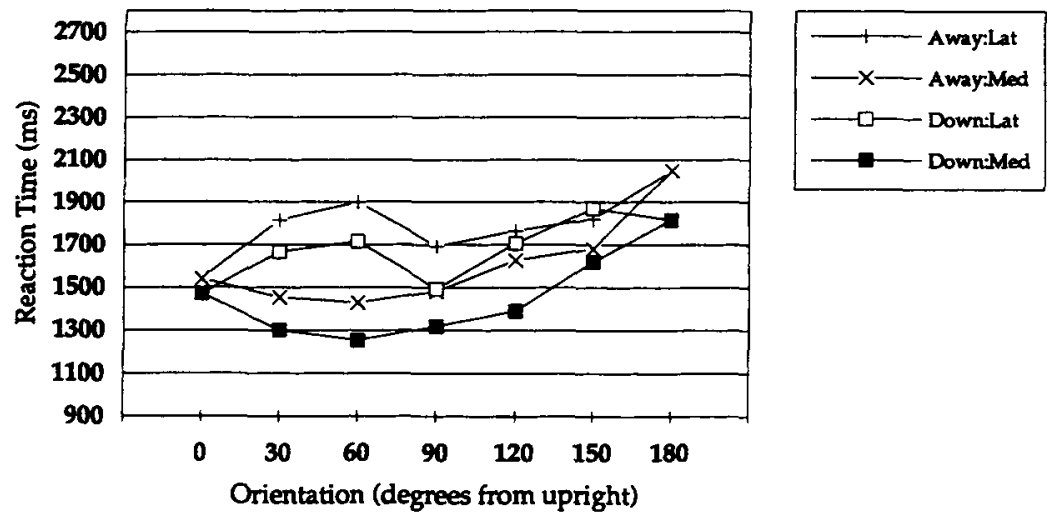

Figure 7, continued.

mimics the time for actually performing corresponding actions.

\section{General Discussion}

People are capable of mentally simulating events representing a wide variety of properties, including moving their body, observing a three-dimensional scene, and spatially transforming or assembling an object (e.g., Decety, Jeannerod, \& Prablanc, 1989; Decety \& Michel, 1989; Finke, Ward, \& Smith, 1992; Gentner \& Stevens, 1983; JohnsonLaird, 1983; Kosslyn, 1990; Parsons, 1987a; Shepard \& Cooper, 1982; Tversky \& Kahneman, 1982). This form of mental representation makes readily accessible information that is otherwise difficult to gain. It provides a way to represent and transform spatial properties of objects and scenes, supporting inferences about possible events and changes in spatial relations among objects in a scene (e.g., de Kleer \& Brown, 1976; Gilden \& Profitt, 1989; Kosslyn, 1990; Landau \& Jackendoff, 1993; Parsons, 1994b; Pinker, 1985; Shepard, 1984). The usefulness and validity of those inferences turns on effective, accurate representation of essential, pervasive properties of the events simulated. The findings reported here reveal that temporal and kinematic properties of many of one's actions are accurately represented in their mental simulations: the kinematic configuration of the body that is represented and transformed corresponds to the actual current kinematic configuration of one's body; the mentally simulated kinematic sensorimotor information is mapped onto perceived visual target information as in actual motion; and the time to mentally simulate one's action is very often proportional or roughly equal to the time for actual motion.

Temporal correspondence between real and mentally simulated action is demonstrated here for natural efficient 
movement from an initial posture where the hand is midway between extremes of each of its joint-limited degrees of freedom into a set of target hand postures that systematically and extensively samples all possible target hand postures. Thus, this correspondence appears to be general, although not uniform. The time for simulated and real movements is roughly equal for target postures that are toward the midline, more common, and more comfortable. However, longer, though proportional, time is required for real movement into less common postures that require longer trajectories, coordinated activity at more joints, motion near extremes of joint-limits, and more uncomfortable kinesthetic sensations. In addition, the correspondence between simulated and real movement time is weakest for the very most awkward and uncommon target hand postures.

Further study is required to determine exactly why the real and mentally simulated times converge and diverge with these movement variables. The more awkward orientations require changes at more than one joint and interactions among such changes, and perhaps the complexity of such structural change surpasses the capacity or precision of the mental simulation processes. If so, then those mental simulations may be more poorly approximated and require proportionally less time than does the corresponding action. It may also be that the mental simulation process is based on less detailed biomechanical information for less familiar target postures, and the default tendency is to produce sketchy, rapid simulations.

Because the kinematic configuration of the body that is represented and transformed in mental simulations of action matches the actual current kinematic configuration of one's body, the representation underlying performance is likely what has been termed "body schema" (Benton, 1985; Frederiks, 1969; Head, 1920; Ogden, 1985; Paillard, 1991; Shontz, 1969). One's body is likely the most complicated and intricate object of which one has detailed mental representations, with many parts and possible configurations, and based on many different kinds of information. The body schema is hypothesized to serve critical integrative functions in organizing and maintaining spatial orientation for perception and action. These and related results show that chronometric paradigms may be used to reveal the properties of these rich mental representations and to yield knowledge useful in neuropsychological settings.

These results generally support a model (Parsons, 1987b) that one mentally simulates one's body movements by representing biomechanically accurate trajectories in a threedimensional space with temporal dynamics comparable to real movement. This is a plausible working hypothesis for a variety of reasons. Motor behavior is likely planned at the object (or end-effector) level rather than at the joint level (Bernstein, 1967; Hollerbach, 1982), so various structures and processes that are involved in preparing an action may be involved in formulating a plan for its mental simulation. Furthermore, processes involved in executing an action (e.g., "motor programs," Arbib, 1991; Brooks, 1979; Keele, 1968; Schmidt, 1975) may be involved in mentally simulating it. In addition, there are various reports showing the effects of mentally simulated practice or performance on later motor performance (e.g., Feltz \& Landers, 1983; Finke, 1979; Johnson, 1982; Richardson, 1967; Yue \& Cole, 1992).

One plausible model of these phenomena is that mental simulation makes use of a forward kinematic map of the arm to make small changes in joint angles (i.e., producing hand position changes by changing joint angles within their limits), then a reasonably efficient movement is developed on the basis of error of that simulation to the target hand posture computed in a body-centered visual frame of reference. Mental simulation time is proportional to the length of the trajectory simulated, probably because time to represent a trajectory is the sum of the times to represent the body parts at regular intermediate positions in the path, and the number of intermediate positions in a path to be represented is proportional to trajectory length (Cooper, 1976; Parsons, $1994 \mathrm{~b}, 1994 \mathrm{c})$. The time required for the mental simulation of an action may be influenced by factors other than extent of motion-for example, factors such as the degree of force, effort, precision, or control apparently involved in that action. The kind of paradigms used here may lead to better understanding of the central and cognitive aspects of motor representation, planning, and preparation.

These findings are consistent in a general if yet vague way with the idea that basic sensorimotor structures participate in the mental simulation of action. Higher cognitive centers may simulate events by producing patterns of activation in (a) the visual or sensorimotor processing areas in the brain that mediate the perception of the shape, orientation, and location of objects and of one's body, and (b) the areas that mediate motor behavior. Findings from neuropsychological patients, functional brain mapping in healthy normals, physiological recordings of implicit autonomic responses, and single cell recordings of populations of neurons in primates are consistent with the hypothesis that underlying mentally simulated action and real action are common structures or functional properties.

In a study of the commissurotomized patient V.P. (Parsons, Gabrieli, \& Gazzaniga, 1993), when one or the other cerebral hemisphere was briefly shown its contralateral hand, she accurately judged its handedness, producing RTorientation functions highly correlated with those of normal subjects (e.g., in Experiment 1 here). When one or the other hemisphere was shown its ipsilateral hand, it was not judged accurately but was misjudged or misperceived as a contralateral hand. Thus, neither hemisphere could access an appropriate representation of the ipsilateral hand, suggesting that cerebrally lateralized, somatic representations of the body interact with higher cognitive and perceptual processes to allow left-right judgment of a hand and to produce mental simulation of motion. Regional cerebral blood flow studies indicate that imagining a well-learned motor sequence selectively activates structures in the supplementary motor area and the cerebellum that are likely involved in planning and programming real action (Roland \& Friberg, 1985; Roland, Larsen, Lassen, \& Skinhoj, 1980; Roland, Skinhoj, Lassen, \& Larsen, 1980; Decety, Sjoholm, Ryding, Stenberg, \& Ingvar, 1990). Mental simulation of specific actions is associated with changes in the involuntary, im- 
plicit processes of cardiac and respiratory activity comparable to that observed in corresponding real actions (Decety, Jeannerod, Germain, \& Pastene, 1991; Requin, Brener, \& Ring, 1991; Wang \& Morgan, 1992). Finally, Georgopoulos and his colleagues (Georgopoulos, Taira, \& Lukashin, 1993; Georgopoulos, Lurito, Petrides, Schwartz, \& Massey, 1989; Pellizzer \& Georgopoulos, 1993) have shown that in the planning of planar arm movements, the "average activation" of a population of primate motor cortex cells (each representing a slightly different direction of movement) represents a movement vector and its rotation over time to a task-specific direction. The most relevant points here are that these findings reveal (a) a neural mechanism in the sensorimotor areas that is involved in the preparation of movement and that produces a continuous rotation of a movement planning vector, (b) that the time for this rotation is approximately linearly proportional to the directed angle of movement, and (c) that the rate of this rotation is comparable to the approximately linear rate for imagining the rotation of a simple two-dimensional object.

In conclusion, a combination of psychophysical, neuropsychological, and brain mapping studies may lead to the development of explicit models of the internally simulated spatial transformations found in sensorimotor phenomenon (Parsons et al., in press; Stein, in press), and ultimately such efforts may contribute detailed models of the mental simulation of events that do not involve one's body. In addition, full understanding of these phenomena may require considering both those aspects of synaptogenesis pertaining to how the functional and structural properties of neurons are affected by their peripheral targets (Purves, 1988) and the evolution of neural systems for self-representation and mimesis (e.g., Donald, 1991).

\section{References}

American Academy of Orthopaedic Surgeons, Committee for the Study of Joint Motion. (1965). Joint motion: Method of measuring and recording. Chicago: American Academy of Orthopaedic Surgeons.

An, C. H., Atkeson, C. G., \& Hollerbach, J. M. (1988). Modelbased control of a robot manipulator. Cambridge, MA: MIT Press.

Arbib, M. A. (1991). Interaction of multiple representations of space in the brain. In J. Paillard (Ed.), Brain and space (pp. 379-404). New York: Oxford University Press.

Ballard, D. (1986). Cortical connections and parallel processing: Structure and function. Behavioral and Brain Sciences, 9, 67-120.

Benton, A. (1985). Body schema disturbances: Finger agnosia and right-left disorientation. In K. M. Heilman \& E. Valenstein (Eds.), Clinical neuropsychology (pp. 115-128). New York: Oxford University Press.

Bernstein, N. (1967). The coordination and regulation of movements. Elmsford, NY: Pergamon Press.

Biederman, I. (1981). Semantics of a glance at a scene. In $\mathbf{M}$. Kubovy \& J. R. Pomerantz (Eds.), Perceptual organization (pp. 213-253). Hillsdale, NJ: Erlbaum.

Bisiach, E., Capitani, E., \& Porta, E. (1985). Two basic properties of space representation in the brain. Journal of Neurology, Neurosurgery and Psychiatry, 48, 141-144.
Brooks, V. B. (1979). Motor programs revisited. In R. E. Talbot \& D. R. Humphrey (Eds.), Posture and movement (pp. 13-49). New York: Raven Press.

Bundesen, C., Larsen, A., \& Farrell, J. E. (1981). Visual transformation of size and orientation: Spatial imagery and perceptual processes. In A. D. Baddeley and J. Long (Eds.), Attention and performance (Vol. 9, pp. 279-294). Hillsdale, NJ: Erlbaum.

Clark, F. J., \& Horch, K. W. (1986). Kinesthesia. In K. R. Boff, L. Kaufman, \& J. P. Thomas (Eds.), Handbook of perception and human performance: Vol. 1. Sensory processes and perception. New York: Wiley.

Cooper, L. A. (1976). Demonstration of a mental analog of an external rotation. Perception \& Psychophysics, 19, 296-302.

Cooper, L. A. (1989). Mental models of the structure of visual objects. In B. E. Shepp \& S. Ballesteros (Eds.), Object perception: Structure and processes (pp. 91-118). Hillsdale, NJ: Erlbaum.

Cooper, L. A., \& Shepard, R. N. (1973). Chronometric studies of the rotation of mental images. In W. G. Chase (Ed.), Visual information processing (pp. 75-176). San Diego, CA: Academic Press.

Cooper, L. A., \& Shepard, R. N. (1975). Mental transformations in the identification of left and right hands. Journal of Experimental Psychology: Human Perception and Performance, 104, 48-56.

Craik, K. J. W. (1943). The nature of explanation. Cambridge, England: Cambridge University Press.

Craver-Lemley, C., \& Reeves, A. (1992). How visual imagery interferes with vision. Psychological Review, 99, 663-649.

Decety, J., Jeannerod, M., Germain, M., \& Pastene, J. (1991). Vegetative response during imagined movement is proportional to mental effort. Behavioral Brain Research, 42, 1-5.

Decety, J., Jeannerod, M., \& Prablanc, C. (1989). The timing of mentally represented actions. Behavioral Brain Research, 34, $35-42$.

Decety, J., \& Michel, F. (1989). Comparative analysis of actual and mental movement times in two graphic tasks. Brain \& Cognition, 11, 87-97.

Decety, J., Sjoholm, H., Ryding, E., Stenberg, G., \& Ingvar, D. (1990). The cerebellum participates in mental activity: Tomographic measurements of regional cerebral blood flow. Brain Research, 34, 313-317.

de Kleer, J., \& Brown, J. S. (1976). Mental models of physical mechanisms and their acquisition. In J. R. Anderson (Ed.), Cognitive skills and their acquisition (pp. 285-310). Hillsdale, NJ: Erlbaum.

Denny-Brown, D., \& Chambers, R. A. (1958). The parietal lobes and behavior. Research Publications for the Association of Research in Mental Disease, 36, 35-117.

Di Pellegrino, G., Fadigo, L., Fogassi, L., Gallese, V., \& Rizzolatti, G. (1992). Understanding motor events: A neurophysiological study. Experimental Brain Research, 91, 176-180.

Donald, M. (1991). Origins of the modern mind: Three stages in the evolution of culture and cognition. Cambridge, MA: Harvard University Press.

Feltz, D. L., \& Landers, D. M. (1983). The effects of mental practice on motor skill learning and performance: A metaanalysis. Journal of Sport Psychology, 5, 25-57.

Finke, R. A. (1979). The functional equivalence of mental images and errors of movement. Cognitive Psychology, 11, 235-264.

Finke, R. A., \& Shepard, R. N. (1986). The visual functions of mental imagery. In K. R. Boff, L. Kaufman, \& J. Thomas (Eds.), Handbook of perception and human performance (Vol. 2). New York: Wiley. 
Finke, R. A., Ward, T. B., \& Smith, S. M. (1992). Creative cognition: Theory, research, and applications. Cambridge, MA: MIT Press.

Franklin, N., \& Tversky, B. (1990). Searching imagined environments. Journal of Experimental Psychology: General, 119, 63-76.

Frederiks, J. A. M. (1969). Disorders of the body schema. In P. J. Vinken \& G. W. Bruyn (Eds.), Handbook of clinical neurology (Vol. 4, pp. 207-240). Amsterdam: North-Holland.

Gallistel, C. R. (1980). The organization of action: A new synthesis. Hillsdale, NJ: Erlbaum.

Gentner, D., \& Stevens, A. L. (1983). Mental models. Hillsdale, NJ: Erlbaum.

Georgopoulos, A. P., Lurito, J. T., Petrides, M., Schwartz, A. B., \& Massey, J. T. (1989). Mental rotation of the neuronal population vector. Science, 243, 234-236.

Georgopoulos, A. P., Taira, M., \& Lukashin, A. (1993). Cognitive neurophysiology of the motor cortex. Science, 260, 47-52.

Gibson, J. J. (1966). The senses considered as perceptual systems. Boston: Houghton Mifflin.

Gilden, D. L., \& Profitt, D. R. (1989). Understanding natural dynamics. Journal of Experimental Psychology: Human Perception and Performance, 15, 372-383.

Goldberg, M. J., \& Bruce, C. J. (1990). Primate frontal eye fields: Maintenance of a spatially accurate signal. Journal of Neurophysiology, 64, 489-508.

Goodale, M. A., Milner, A. D., Jakobson, L. S., \& Carey, D. P. (1991). Perceiving the world and grasping it: A neurological dissociation. Nature, 349, 154-156.

Gottlieb, G. L., Corcos, D. M., \& Agrawal, G. C. (1989). Strategies for the control of voluntary movements with one mechanical degree of freedom. Behavioral and Brain Sciences, I2, 189-250.

Head, H. (1920). Studies in neurology (Vol. 2). London: Oxford University Press.

Hinton, G. E., \& Parsons, L. M. (1981). Frames of reference and mental imagery. In A. D. Baddeley \& J. Long (Eds.), Attention and performance (Vol. 9, pp. 261-277). Hillsdale, NJ: Erlbaum.

Hinton, G. E., \& Parsons, L. M. (1988). Scene-based and viewercentered representations for comparing shape. Cognition, 30 , $1-35$.

Hollerbach, J. M. (1982). Computers, brains, and the control of movement. Trends in Neuroscience, 5, 189-192.

Hollerbach, J. M. (1990). Fundamentals of motor behavior. In D. Osherson (Ed.), Invitation to cognitive science (Vol. 2, pp. 151-182). Cambridge, MA: MIT Press.

Howard, I. P. (1986). The perception of posture, self motion, and the visual vertical. In K. R. Boff, L. Kaufman, \& J. P. Thomas (Eds.), Handbook of perception and performance: Volume 1. Cognitive processes and performance. New York: Wiley.

Jeannerod, M. (1984). The timing of natural prehension movements. Journal of Motor Behaviour, 16, 235-254.

Jeannerod, M. (1988). The neural and behavioral organization of goal-directed movements. New York: Oxford University Press.

Johnson, P. (1982). The functional equivalence of imagery and movement. Quarterly Journal of Experimental Psychology, 34A, 349-365.

Johnson-Laird, P. N. (1983). Mental models: Towards a cognitive science of language, inference, and consciousness. Cambridge, MA: Harvard University Press.

Jolicoeur, P. (1985). Time to name misoriented natural objects. Memory and Cognition, 13, 289-303.

Kawato, M., Maeda, Y., Uno, Y., \& Suzuki, R. (1990). Trajectory formation of arm movement by cascade neural network model based on minimum torque-change criterion. Biological $C y$ bernetics, 62, 275-288.

Keele, S. W. (1968). Movement control in skilled motor performance. Psychological Bulletin, 70, 387-403.

Kelso, J. A. S. (1978). Joint receptors do not provide a satisfactory basis for motor learning and positioning. Psychological Review, $85,474-481$.

Klatsky, R. L., McCloskey, B., Doherty, S., Pellegrino, J., \& Smith, T. (1987). Knowledge about hand shaping and knowledge about objects. Journal of Motor Behavior, 19, 187-213.

Kosslyn, S. M. (1990). Mental imagery. In D. Osherson (Ed.), Invitation to cognitive science (Vol. 2, pp. 73-97). Cambridge, MA: MIT Press.

Lackner, J. R. (1988). Some proprioceptive influences of the perceptual representation of body shape and orientation. Brain, 111 , 281-297.

Lacquaniti, F. (1989). Central representations of human limb movement as revealed by studies of drawing and handwriting. Trends in Neuroscience, 12, 287-291.

Landau, B., \& Jackendoff, R. (1993). "What" and "where" in spatial language and spatial cognition. Behavioral and Brain Sciences, 16, 217-238.

Lowe, D. (1987). The viewpoint consistency constraint. International Journal of Computer Vision, 1, 57-72.

Marr, D., \& Vaina, L. (1982). Representation and recognition of the movements of shapes. Proceedings of the Royal Society of London, Series B, 214, 501-524.

Ogden, J. (1985). Autotopagnosia. Brain, 108, 1009-1022.

Paillard, J. (1991). (Ed.). Brain and space. New York: Oxford University Press.

Palmer, S. (1989). Reference frames in the perception of shape and orientation. In B. E. Shepp \& S. Ballesteros (Eds.), Object perception: Structure and processes (pp. 121-161). Hillsdale, NJ: Erlbaum.

Palmer, S., Rosch, E., \& Chase, P. (1981). Canonical perspective and the perception of objects. In J. Long \& A. Baddeley (Eds.), Attention and performance (Vol. 9, pp. 135-151). Hillsdale, NJ: Erlbaum.

Parsons, L. M. (1987a). Imagined spatial transformation of one's body. Journal of Experimental Psychology: General, 116, 172-191.

Parsons, L. M. (1987b). Imagined spatial transformation of one's hands and feet. Cognitive Psychology, 19, 178-241.

Parsons, L. M. (1987c). Visual discrimination of abstract, threedimensional objects at many orientations. Perception \& Psychophysics, 42, 49-59.

Parsons, L. M. (1990). Body image. In M. W. Eysenck (Ed.), The Blackwell dictionary of cognitive psychology (pp. 46). Oxford, England: Basil Blackwell.

Parsons, L. M. (1994a). Knowing when it's right: Evidence for rapid preattentive perception of the handedness of a visual stimulus. Manuscript submitted for publication.

Parsons, L. M. (1994b). New psychophysical constraints on theories of how an object's orientation and rotation are mentally represented. Manuscript submitted for publication.

Parsons, L. M. (1994c). Time to mentally represent an object's shape in a rotation varies widely in a linear gradient with orientation. Manuscript submitted for publication.

Parsons, L. M., \& Chou, K.-L. (1994). The left-right judgment of an ear and of an eye. Manuscript submitted for publication.

Parsons, L. M., Fox, P. T., Downs, J. H., Glass, T., Hirsch, T., Martin, C., Jerabek, P., \& Lancaster, J. L. (in press). Implicit movement enables discrimination of visual object shape: Evidence from PET studies. Society for Neuroscience Abstracts. 
Parsons, L. M., Gabrieli, J. D. E., \& Gazzaniga, M. (1993). Each cerebral hemisphere supports discrimination, and imagined actions of, the contralateral but not ipsilateral hand. Unpublished manuscript.

Parsons, L. M., \& Shimojo, S. (1987). Perceived spatial organization of cutaneous patterns on surfaces of the human body in various positions. Journal of Experimental Psychology: Human Perception and Performance, 13, 488-504.

Parsons, L. M., \& Shimojo, S. (1994). Spatial information processing in the cutaneous perception and motor production of patterns. Manuscript submitted for publication.

Pellegrino, J. W., Klatzky, R. L., \& McCloskey, B. P. (1989). Time course of preshaping for functional responses to objects. Journal of Motor Behaviour, 21, 307-316.

Pellizzer, G., \& Georgopoulos, A. P. (1993). Common processing constraints for visuomotor and visual mental rotations. Experimental Brain Research, 93, 165-172.

Perrett, D. I., Smith, P. A., Potter, D. D., Mistlin, A. J., Head, J. S., Milner, A. D., \& Jeeves, M. A. (1985). Visual cells in the temporal cortex sensitive to face view and gaze direction. Proceedings of the Royal Society of London, Series B, 223, 293317.

Pinker, S. (Ed.). (1985). Visual cognition. Cambridge, MA: MIT Press.

Purves, D. (1988). Body and brain: A trophic theory of neural connections. Cambridge, MA: Harvard University Press.

Requin, J., Brener, J., \& Ring, C. (1991). Preparation for action. In J. R. Jennings \& M. G. H. Coles (Eds.), Handbook of cognitive psychophysiology. Central and autonomic nervous system approaches (pp. 357-448). New York: Wiley.

Richardson, A. (1967). Mental practice: A review and discussion, Parts 1 \& 2. Research Quarterly, 38, 95-107, 262-273.

Rizzolatti, G., Camarda, R., Fogassi, L., Gentilucci, M., Luppino, G., \& Matelli, M. (1988). Functional organization of area 6 in the macaque monkey. II Area F5 and the control of distal movements. Experimental Brain Research, 71, 491-507.

Rock, I. (1973). Orientation and form. San Diego, CA: Academic Press.

Rock, I. (1986). The description and analysis of object and event perception. In K. R. Boff, L. Kaufman, \& J. P. Thomas (Eds.), Handbook of perception and human performance: Vol. 1. Sensory processes and perception. New York: Wiley.

Roland, P. E., \& Friberg, L. (1985). Localization of cortical areas activated by thinking. Journal of Neurophysiology, 53, 12191243.

Roland, P. E., Larsen, B., Lassen, N. A., \& Skinhoj, E. (1980). Supplementary motor area and other cortical areas in organization of voluntary movements in man. Journal of Neurophysiology, 43, 118-136.

Roland, P. E., Skinhoj, E., Lassen, N. A., \& Larson, B. (1980). Different cortical areas in man in organization of voluntary movement in extrapersonal space. Journal of Neurophysiology, 43, 137-150.

Rosenbaum, D. A. (1991). Human motor control. San Diego, CA: Academic Press.

Rosenbaum, D. A., Marchak, F., Barnes, H. J., Vaughan, J., Slotta, J. D., \& Jorgensen, M. J. (1990). Constraints for action selection. Overhand versus underhand grips. In M. Jeannerod (Ed.), Motor representation and control: Attention and performance (Vol. 13, pp. 321-342). Hillsdale, NJ: Erlbaum.
Saltzman, E. L. (1979). Levels of sensorimotor representation. Journal of Mathematical Psychology, 20, 91-163.

Saltzman, E. L., \& Kelso, J. A. S. (1987). Skilled actions: A taskdynamic approach. Psychological Review, 94, 84-106.

Schmidt, R. A. (1975). A schema theory of discrete motor skill learning. Psychological Review, 82, 225-260.

Schmidt, R. A. (1988). Motor control and learning. Champaign, IL: Human Kinetics Publishers.

Sedgewick, H. A. (1986). Space perception. In K. R. Boff, L. Kaufman, \& J. P. Thomas (Eds.), Handbook of perception and performance: Vol. 2. Cognitive processes and performance. New York: Wiley.

Sekiyama, K. (1982). Kinesthetic aspects of mental representation in the identification of left and right hands. Perception \& Psychophysics, 32, 89-95.

Shepard, R. N. (1984). Ecological constraints on internal representation: Resonant kinematics of perceiving, imagining, thinking, and dreaming. Psychological Review, 91, 417-447.

Shepard, R. N., \& Cooper, L. A. (1982). Mental images and their transformations. Cambridge, MA: MIT Press.

Shepard, R. N., \& Hurwitz, S. (1984). Upward direction, mental rotation, and discrimination of left and right turns in maps. Cognition, 18, 161-193.

Shepard, R. N., \& Metzler, J. (1971). Mental rotation of three dimensional objects. Science, 191, 952-954.

Shontz, F. C. (1969). Perceptual and cognitive aspects of body experience. San Diego, CA: Academic Press.

Soechting, J. F. (1989). Sensorimotor representations for pointing to target in 3D space. Journal of Neurophysiology, 62, 582-594.

Soechting, J. F., \& Lacquaniti, F. (1981). Invariant characteristics of a pointing movement in man. Journal of Neuroscience, $I$, $710-720$

Stein, J. F. (in press). Posterior parietal cortex and egocentric space. Behavioral and Brain Sciences.

Taira, M., Mine, S., Georgopoulos, A. P., Murata, A., \& Sakata, H. (1990). Parietal cortex neurons of the monkey related to the visual guidance of hand movements. Experimental Brain Research, 83, 29-36.

Tarr, M. J., \& Pinker, S. (1989). Mental rotation and orientationdependence in shape recognition. Cognitive Psychology, 21, 233-282.

Tversky, A., \& Kahneman, D. (1982). Judgments of and by representativeness. In D. Kahneman, P. Slovic, \& A. Tversky (Eds.), Judgment under uncertainty: Heuristics and biases (pp. 84-98). Cambridge, England: Cambridge University Press.

Ullman, S. (1989). Aligning pictorial descriptions. Cognition, 32 , 193-254.

Viviani, P., \& McCollum, G. (1983). The relation between linear extent and velocity in drawing movements. Journal of Neuroscience, 10, 211-218.

Wang, Y., \& Morgan, W. P. (1992). The effects of imagery perspectives on the physiological responses to imagined exercise. Behavioral Brain Research, 52, 167-174.

Weiskrantz, L. (1986). Blindsight: A case study and its implications. New York: Oxford University Press.

Yue, G., \& Cole, K. J. (1992). Strength increases from the motor program: Comparison of training with maximal voluntary and imagined muscle contractions. Journal of Neurophysiology, 67, 1114-1123. 


\section{Appendix \\ Preattentive Processing Guides the Exact Match Confirmation Used in Handedness Judgment}

Although the phenomenon seems puzzling or paradoxical, Parsons's $1987 \mathrm{~b}$ results strongly suggest that in the early preattentive stages of information processing accurate information about stimulus handedness is present (though not available for conscious processing), and that later mental simulation and shape-matching operations provide confirmation for conscious decision-making. Evidence indicates that subjects use exact match confirmation in making a left-right judgment of a body part (Parsons, 1987a, 1987b). Consistent use of such a disconfirmation strategy is clearly contradicted by response times because, for example, checking a dominant hand against the stimulus and inferring from a mismatch that it is the other hand would produce RT-orientations for trials with the nondominant hand that reflected joint constraints of the dominant hand, a prediction firmly refuted by data in several experiments from many subjects. Furthermore, when subjects are asked how often they had imagined the wrong hand at the orientation of the stimulus, they reported doing so rarely- $13.25 \%$ of the trials. They reported very often imagining their left hand for left-hand stimuli and their right hand for right-hand stimuli$86.00 \%$ of the trials.

Finally, Parsons's (1994a) findings confirm this hypothesis. Subjects in this study were briefly presented a single hand and were required to make a judgment (or "best guess") within a deadline period indicated by tones. Five deadlines varied randomly across trials, often interrupting subjects' performance prior to the time at which they could begin to mentally simulated their hand moving into the orientation of the stimulus. For the very shortest deadline (125 ms) subjects' accuracy was at chance. However, by
.50 of each subject's fastest RT mean under "free-viewing" conditions (i.e., like that in Experiment 1 here), their left-right judgment was .75 accurate on average across stimuli; by .68 of each subject's fastest "free-viewing" RT mean, their judgment was .85 accurate on average and above chance on all stimuli.

Performance in the left-right judgment task appears to involve these operations, some of which may occur concurrently: (a) analysis of the orientation and handedness of the stimulus; (b) analysis of the orientation of the internally represented corresponding hand; (c) planning a path for the internally represented hand to move (within its joint constraints) to the orientation of the stimulus; (d) mental simulation of planned action; and (e) exact-match confirmation of shape of imagined and perceived hands.

The early implicit knowledge about stimulus handedness may be the result of analysis utilizing associations among object or hand shape and action patterns (see various suggestive findings by Di Pellegrino, Fadiga, Fogassi, Gallese, \& Rizzolatti, 1992; Jeannerod, 1984; Klatsky, McCloskey, Doherty, Pellegrino, \& Smith, 1987; Pellegrino, Klatzky, \& McCloskey, 1989; Rizzolatti et al., 1988; Rosenbaum et al., 1990; Taira, Mine, Georgopoulos, Murata, \& Sakata, 1990). This phenomenon appears reminiscent of reports of implicit knowledge derived from sensorimotor processing (e.g., Goodale, Milner, Jakobson, \& Carey, 1991; Weiskrantz, 1986).

Received January 29, 1993

Revision received June 17, 1993

Accepted September 4, 1993 